\title{
LA POBLACIÓN HISPANA EN ESTADOS UNIDOS DE AMÉRICA* Asimilación y diferencia
}

\author{
MARÍA JESÚS CRIADO
}

Instituto Universitario Ortega y Gasset

PALABRAS CLAVE ADICIONALES

Hispanos en Estados Unidos, Pluralismo

cultural, Transnacionalismo.

\author{
ADDITIONAL KEYWORDS \\ Hispanic Population, Cultural Pluralism, \\ Transnationalism.
}

RESUMEN. El incremento sostenido de la población de origen o ascendencia latinoamericana en Estados Unidos está suscitando un extenso debate sobre la capacidad asimiladora de la sociedad americana y su evolución en cuanto conjunto diferenciado. En el texto se repasan los datos y notas más destacados de esta población en varias vertientes anotando, a partir de ellos, hacia dónde parece apuntar dicha evolución.

SUMMARY. The sustaining growth of Latin-American origin or ancestry population in the United States is causing an extensive debate about the absorbing ability of the American society and its evolution as a differentiated whole. In the following text, some outstanding data and notes from this population are reviewed from different perspectives, deducing from them where this evolution seems to be leading.

\footnotetext{
*Este estudio se efectuó durante una estancia como Visiting Research Fellow en el Centro sobre Migración y Desarrollo de la Universidad de Princeton y contó con una beca post-doctoral de la Secretaría de Estado de Educación y Universidades (MECD) y con el apoyo de dicho Centro. Una versión inicial fue publicada por el Real Instituto Elcano con el título "Perdurará lo hispano en USA" (Documentos de Trabajo 2002-8, Madrid 2002).

E-mail: mjcriado@jazzfree.es
}

Revista Internacional de Sociología (RIS)

Tercera Época, No 36, Septiembre-Diciembre, 2003, pp. 171-206. 
RIS

REVISTA INTERNACIONAL DE SOCIOLOCIA

№ 36, Septiembre-Diciembre, 2003

MARÍA JESÚS CRIADO

El 21 de enero de 2003, la Oficina del Censo de los Estados Unidos daba carácter oficial a un hecho histórico: con 37 millones a 1 de junio de 2001 -que serían más de 40 de sumar los casi 4 millones de Puertorrico-, el conjunto de grupos hispanos se erigía en la mayor de las minorías relevando a la afro-americana (36,2 millones). Con ello ratificaba el cambio de escenario demográfico, que ya anticipaban los primeros datos del Censo 2000. Y si en 2002 esa variopinta población, que se amalgama bajo una sola etiqueta, suponía el 13,3\% de la total, cálculos de la Oficina del Censo estiman que rondará los 60 millones en 2020 y superará los 100 (el 24\%) a mitad de siglo. Esto significa que en esta misma década Estados Unidos tendrá la segunda población latina del mundo y que se triplicará de aquí a 2050.

De modo que si la potente inmigración de la última década está cambiando "la cara de América", como destacan los medios de comunicación dell país, los sucesivos informes de la Oficina del Censo y los institutos especializados no dejan de subrayar el liderazgo del bloque latino en esa transformación. Con una tasa de crecimiento muy superior a la nacional $-58 \%$ y $13 \%$, de 1990 a 2000 , en una y otra-, la comunidad hispana se afirma como la más numerosa y la que presenta un desarrollo más fuerte y sostenido, un hecho del que han tomado buena nota los agentes sociales y del que derivan importantes efectos sociales, económicos y políticos.

Las consecuencias a largo plazo de este giro y el impacto que ello pueda tener en ambos polos es algo de lo que sólo el tiempo podrá darnos razón. Si bien, una de las cuestiones que más debates suscita es cuál será el futuro de esa comunidad una vez se conforme un stock relativamente estable. $\mathrm{O}$, en otras palabras, si la máquina asimiladora será igual de eficaz que en la otra gran ola migratoria y los inmigrantes sufrirán un proceso de aculturación análogo, perdiendo lengua y cultura, o rebatirán tal precedente $\mathrm{y}$, aún integrándose en el conjunto general, conservarán éstas promoviendo con ello la conversión de Estados Unidos en un país bilingüe. Un futuro virtual que se opone a la secular tendencia asimiladora de ese país y que despierta no pocas dudas en buen número de escépticos; aunque también crecientes temores entre los partidarios del clásico - y hoy día un tanto devaluado-melting pot.

Parece evidente que la respuesta a tal cuestión ha de venir de la mano de la segunda y ulteriores generaciones. Y si atendemos sólo a este factor, el resultado parece fuera de toda duda apuntando, claramente, a favor de la primera hipótesis. En efecto, distintos trabajos reflejan el declive de la lengua materna entre los hijos de los inmigrantes que culmina en la tercera generación; ésta lo abandona totalmente dado su escaso dominio y falta de apoyo dentro y fuera del hogar (Veltman, 1983). Si bien, aunque los jóvenes le vuelvan la espalda, la presencia del español - vocero cardinal de lo hispano - es cada vez más patente en la vida cotidiana. Máquinas expendedoras de billetes, cajeros automáticos, anuncios, indicadores y avisos, medios de comunicación, grandes compañías y servicios públicos lo van 
incorporando gradualmente y, con ello, normalizando cada vez más su uso. Por lo que, a pesar de tan adversos augurios, no parece que a priori debamos descartar tan pronto la segunda opción. Pues, a la vez que la presión ambiental lleva a la homogenización, las dinámicas generadas en su torno pueden interferir, en alguna medida, en tal tendencia contribuyendo a ratificar la peculiaridad del conjunto. No hay que dejar de lado, por otra parte, la incidencia de otras variables, bien de índole social (modelos instituidos), histórica (trayectorias de los contextos), o de orden cultural como es la tradición del mestizaje, un eje central en el universo latinoamericano.

A intentar aportar algo de luz a esta cuestión van dirigidas las siguientes páginas. En ellas combinamos las fuentes secundarias con observaciones de nuestro estudio en Nueva York ${ }^{1}$ para trazar un cuadro sucinto - a escala demográfica, económica y política - de la población latina en Estados Unidos, atendiendo también a los aspectos expresivos (identidad, lengua y afiliación). Ello nos permitirá avanzar alguna hipótesis sobre su rumbo a más largo plazo.

\section{LA VARIABLE DEMOGRÁFICA}

En octubre de 1965, y a la sombra del movimiento de derechos civiles, tuvo lugar un cambio sustancial en las políticas de inmigración de los Estados Unidos. Se derogaron entonces las llamadas leyes de los Origenes Nacionales $^{2}$, vigentes durante cuatro décadas, implantando un nuevo sistema de distribución de visas que atendía a los criterios de reagrupación familiar, habilidades profesionales y asilo político y fijaba un límite inicial de 20.000 inmigrantes anuales por país. Con ello no sólo se posibilitó un cambio de tendencia en el stock de inmigrantes - que alcanza la cota más baja de la historia en 1970, cuando suman 9,4 millones y suponen menos del 5\% del total-, también abrió la puerta a una revolución demográfica que acabaría transformando la estructura étnica de la nación al dar entrada a un cuantioso flujo de América Latina y Asia. Desde entonces la población foránea ha aumentado velozmente y supera, según el Censo 2000, los 31 millones, el $11,1 \%$ de la población total. Algo más de la mitad (52\%) procede de Latinoamérica. En 1990 eran 8,4 millones (el 44,3\% de foráneos); diez años antes representaban

\footnotetext{
'Éste comprendió observación participante y entrevistas en profundidad a inmigrantes e informantes clave, con especial atención a los conjuntos mexicano y dominicano y se efectuó entre febrero de 2002 y marzo de 2003.

${ }^{2}$ Promulgadas en 1921 y 1924 y ratificadas en el Acta de Inmigración y Nacionalidad de 1952, éstas establecían un sistema de cuotas por origen nacional que favorecía a los países occidentales y limitaba severamente la inmigración. (Schmidley \& US Census Bureau: Profile of the Foreign-Born Population.. 2000: 8-9).
} 
un tercio y menos de un quinto en 1970 (ibidem, pp.10-11). La escalada ha sido, pues, fulminante (gráfico 1).

La estructura de la población extranjera ha dado un vuelco radical en este lapso. La tasa de europeos cae del $75 \%$ en 1960 al $15 \%$ en 2000 sumando 4,4 millones frente a los 7,3 previos. Y aunque el sector asiático advierte también un gran desarrollo y supone - con 7,2 millones- la cuarta parte del conjunto, lo vela el latino. China, el país emisor más importante de esa región y segundo en la lista de nacionalidades, aporta 1,4 millones, seis veces menos que México, el principal emisor. Sus nativos - unos 8 millones - constituyen algo más de la cuarta parte de la población foránea $(27,6 \%)$ y más de la mitad $(66,1 \%)$ del segmento latino. Hay que remontarse al censo de 1890 - cuando el $30 \%$ procedía de Alemania - para encontrar un índice tan elevado de una nacionalidad. En la lista de primeros emisores figura también Cuba (952.000), El Salvador (765.000) y la República Dominicana (692.000) en $5^{\mathrm{a}}, 7^{\mathrm{a}}$ y $9^{\mathrm{a}}$ posición. Por regiones, casi 10 millones proceden de América Central, cerca de otros dos nacieron en el Caribe, y una cifra similar en Sudamérica (Schmidley y US Census Bureau, 2001).

Gráfico 1.

Población extranjera según origen: 1970-2000 (\%)

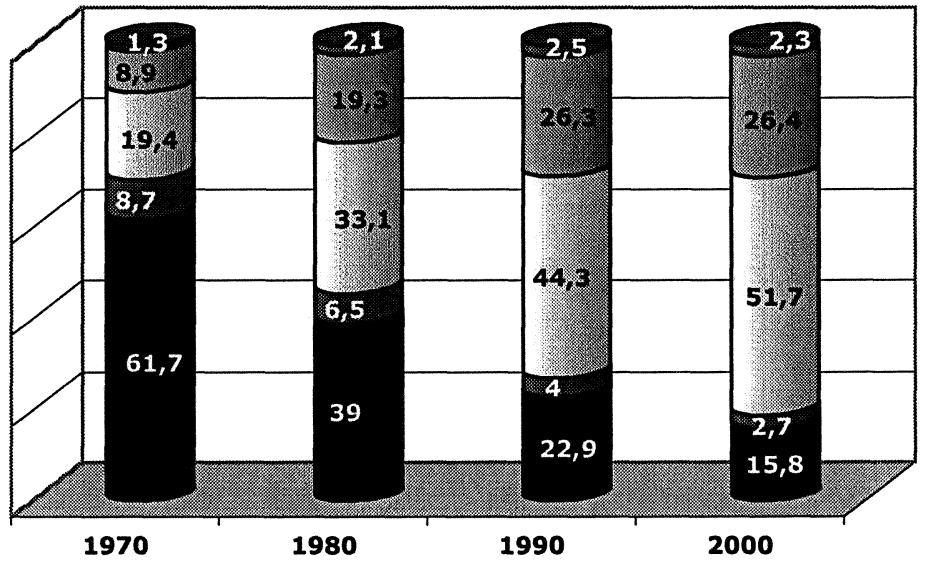

Europa A. Norte DA. Latina DAsia DOtras Áreas

Fuente: Oficina del Censo, 2001, tabla 2 y tabla 1-1; Censo 2000, Summary File 3. 
Casi la cuarta parte de la población foránea son "indocumentados", otra tendencia clave de la migración actual que se expande en los últimos años. Un estudio del Urban Institute estimaba su cifra en 2002 en más de 9 millones (Passell et al., 2004), lo que supone una media anual de medio millón. Y también entre ellos destacan los nacidos en América Latina: de allí son 3 de cada cuatro (el $77 \%$ ). Sólo los mexicanos sumarían unos 5 millones (el $57 \%$ del total) y el resto de países latinos reúnen otros 2 millones (el 22\%). Las otras áreas geográficas están a suficiente distancia. Asia aportaría 1,1 millón (el 10\%), Europa y Canadá medio (6\%), y África y resto de orígenes, el 2\% restante (Passel, 2002 y 2004).

Según Suárez-Orozco (1999), tras este sistema de inmigración inter-americano hay tres cuadros sociales: a) un flujo a gran escala, más o menos regular, desde México que se intensifica a partir de 1980; b) oleadas puntuales desde América Central y del Sur, unidas con frecuencia a conflictos políticos; y c) un patrón caribeño de migración circular tipificado en las experiencias de puertorriqueños y dominicanos. Las condiciones estructurales -efectos de la globalización y reestructuración económica en los países emisores y dependencia de la economía de Estados Unidos de la mano de obra migrante- apuntan a una continuidad de los flujos de esas latitudes, de modo que, aún en el caso de un eventual descenso, los latinoamericanos seguirán siendo dominantes.

En cuanto al cómputo global, en 2002 las estadísticas oficiales registraron 37,4 millones de hispanos (Ramírez et al., 2003). Esto es, el 70\% más que en 1990, cuando sumaban 22,4 millones, y casi el triple que en 1980 (ver gráfico 2). La distribución por nacionalidades es fiel reflejo de la señalada para los inmigrados ya que representan el $40 \%$. Más de 25 millones (el 67\%) son de origen o ascendencia mexicana. Muy por detrás le siguen Puerto Rico (unos 3.6 millones), Cuba (1.3), El Salvador y República Dominicana (alrededor de 1.1 millón cada uno).

Lo más destacado a este respecto es un giro en la composición, fruto del desarrollo, en la pasada década, de los flujos menores ${ }^{3}$. Los "nuevos latinos" pasan de 4,5 millones a cerca de 8 entre 1990 y 2002 perdiendo, así, peso en la suma global los grupos medios tradicionales (tabla 1). Ello añade aún más diversidad al universo hispano y, por ende, una mayor dificultad para hablar de él en general, dada la variedad de perfiles y marcados contrastes que presentan los miembros de cada grupo.

Por otra parte, si los factores implicados auguran larga vida al sistema migratorio, la juventud y el elevada natalidad de la población ratifican la tendencia ascendente del conjunto. En efecto, las mujeres hispanas detentan la tasa de

\footnotetext{
${ }^{3}$ Algunos de los cambios metodológicos introducidos en el censo 2000 causaron bastante debate al aparecer subestimadas algunas nacionalidades de América Central y del Sur. Entre ellos, salvadoreños, guatemaltecos, dominicanos, colombianos y ecuatorianos. Ello dio lugar a numerosas protestas desde diversas organizaciones.
} 
Gráfico 2.

Evolución de la población hispana: 1970-2002

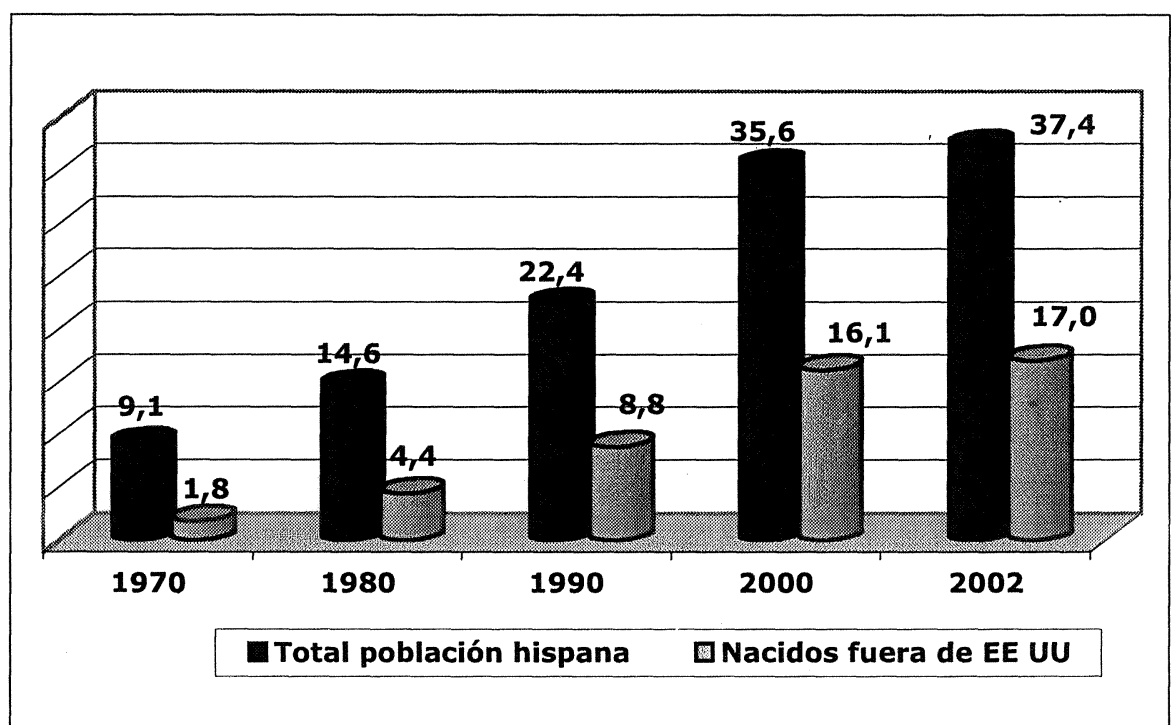

Fuente: Oficina del Censo de los Estados Unidos. (Datos en millones)

Tabla 1.

Distribución de la población hispana según origen: 1990-2002

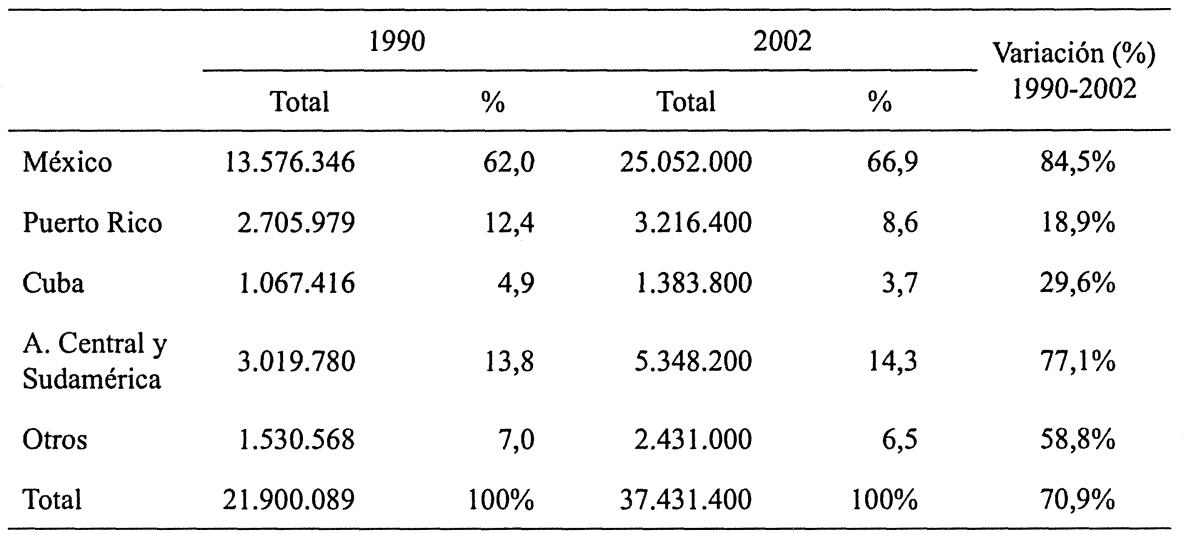

Fuente: Oficina del Censo de los Estados Unidos. Elaboración Propia [E. P.]. 
fertilidad más alta de los distintos segmentos. Así, en 2000, ésta fue de 3,51 nacimientos por mujer (para la primera generación de hispanos) frente a 1,84 de media en la población blanca, superando la observada entre afro-americanas $(2,53)$ e inmigrantes asiáticas $(2,60)$ (Bachu y O'Conell, 2001). Teniendo en cuenta que abundan los menores de 18 años (34\%) -doce puntos por encima del índice a escala nacional $(22,8 \%)$ - y su edad media es 10 años inferior a la global $(25,9$ y 35,3 respectivamente), la unión de ambas variables apunta claramente a un crecimiento sostenido.

Un ejemplo del peso del primer factor citado lo ofrece California, uno de los Estados más poblados (34 millones) y también el que cuenta con mayor población hispana (11 millones). La tercera parte de sus habitantes es de origen latinoamericano (32\%) y, a su vez, allí vive 1 de cada 3 hispanos residentes en Estados Unidos. La pasada década su población se incrementó en 4,1 millones pero, a diferencia de otras zonas, el grueso se debió a los nacimientos mientras la inmigración sólo aportó un $17 \%$. De hecho, según un estudio de la Universidad de California, más de la mitad $(50,6 \%)$ de los nacidos en California en el último trimestre de 2001 eran de origen latino, un dato significativo y con notables implicaciones futuras (Hayes-Bautista et al., 2003).

La concentración es, por otra parte, uno de los rasgos de la población hispana que se congrega - como es usual en los inmigrantes- en ciertas zonas, que varían según su procedencia. Así, en 2000, algo más de tres cuartas partes $(27,1$ millones) residía en siete Estados. Esto es, junto a California, Tejas (6,7 millones); Nueva York (2,9); Florida (2,7); Illinois $(1,5)$; Arizona $(1,3)$ y Nueva Jersey $(1,1)$. Aunque es Nuevo México el que presenta un mayor índice -el $42,1 \%$ de su población es de origen hispano- con claro dominio de mexicanos, al igual que ocurre en California, Texas, Arizona, Illinois y Colorado. En Florida destacan los cubanos, y los puertorriqueños en Nueva York y Nueva Jersey. Fuera de los Estados citados, hay concentraciones significativas en los condados de Washington, Idaho, Wyoming, Utah, Carolina del Norte, Georgia, Iowa, Arkansas, Nebraska, Minnesota y otros Estados no tradicionales de población hispana. En algunos de ellos suponían entre el $6,0 \%$ y el $24,9 \%$ de la población total.

Es ésta, a su vez, la nota más relevante de la evolución del colectivo en la última década: la extensión a zonas impensables hace diez años que advierten, en una buena parte, aumentos muy superiores a las tradicionales. En efecto, según un estudio de Suro y Singer (2002), aunque las metrópolis latinas establecidas (Nueva York, Los Ángeles, Miami y Chicago), observen las mayores alzas en cifras absolutas en este lapso, son los nuevos destinos, y en particular ciudades de tamaño medio, con una base pequeña de partida, los que aumentan en mayor medida. En Atlanta, por ejemplo, con una población latina en 1980 de unos 24.000 , se incrementan en un $995 \%$, sumando casi 270.000 en el año 2000 . O el área de Raleigh-Durham, en el Norte de Carolina, en donde se advierte más del 1000\% de incremento, pasando de 5.670 a 93.868 en el mismo periodo. Suro y Singer 
identifican 51 nuevas áreas que atañen a 35 estados; en dieciocho, la subida supera el 300\%. Entre éstas se encuentran ciudades como Nashville (Tennessee), Portland (Oregon), Washington DC, Indianápolis, Providence (Rhode Island), Orlando y las Vegas (gráfico 3). El proceso afecta asimismo a la distribución en las áreas metropolitanas. Las periferias, y en particular los nuevos destinos, superan también allí, en crecimiento relativo, a los núcleos centrales. En Chicago, por ejemplo, el $63 \%$ del ascenso se produjo en los suburbios y en Miami alcanzó el 96\%. Por otro lado, uno de los rasgos del nuevo patrón es el predominio de varones, lo que apunta a un mayor desarrollo a medio plazo fruto de la reagrupación familiar y la creación de familias (Suro y Singer, 2002).

Ello no implica, por otra parte, una involución en los focos previos. Santa Ana, por ejemplo, una ciudad de 320.000 habitantes en California, tenía en 1980 igual población latina que blanca (44\%). En el censo 2000 la segunda cae al $11 \%$ mientras la latina sube al $76 \%$. En Los Ángeles, en donde constituían el $28 \%$ hace 2 décadas, suponen ya el 46,5\%. El número de áreas en las que minoría y mayoría acortan distancias, o incluso invierten los términos, como ilustran estos ejemplos, empieza a ser menos anecdótico. De hecho, según un estudio del Brookings Institution (2001), los blancos no hispanos se han convertido en la nueva

Gráfico 3.

Distribución territorial de la población hispana 1990-2000

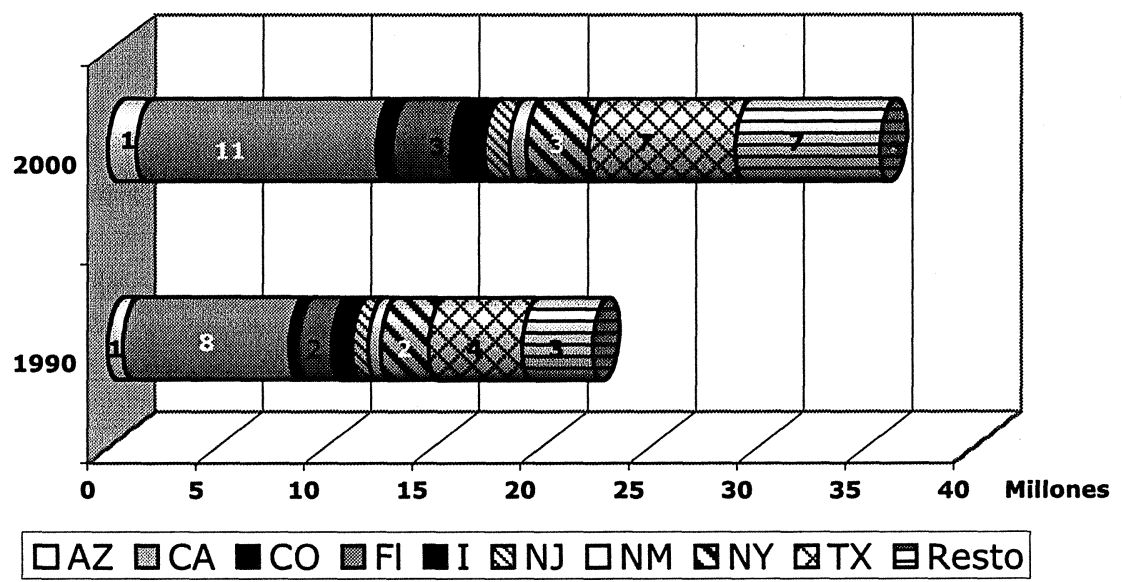

Fuente: Oficina del Censo de los Estados Unidos. Censo 1990 y 2000. [E.P]. 
minoría en las 100 mayores urbes del país. Del $52 \%$ en 1990, bajan al $44 \%$ en 2000 , menos que la suma agregada de afroamericanos $(24 \%)$, hispanos $(23 \%)$ y asiáticos (7\%). De ahí que se empiece a cuestionar la terminología y se busquen nuevas definiciones para "minoría".

Hablamos, pues, de una población elevada, en crecimiento sostenido, muy concentrada y que se extiende por la geografia. Todo ello es importante para el tema que nos ocupa. Pues, mientras volumen, desarrollo y difusión afirman el rango y dimensión del fenómeno al avalar su proyección futura y alcance nacional, la concentración tiene una serie de efectos - hacia dentro y hacia fuera- que atañen directamente a nuestra cuestión. Y ello es así por varias razones. Una es que facilita la conservación de la lengua y otras pautas culturales al conformar un medio en el que constituyen lo habitual. Asimismo, según aumentan los signos de una presencia específica -comercios, asociaciones, restaurantes, centros de reunión, etc.-, dicha zona se constituye en un marco espacial que se identifica con el mismo - frente a los otros-y le dota de un cierto territorio, lo que añade el nivel simbólico, una dimensión que acaba tomando forma ${ }^{4}$.

Pero, además, a partir de cierto punto, adquieren la suficiente masa crítica para ejercer un peso en la economía del área (y generar incluso sus propias redes de abastecimiento y servicios), en los servicios públicos y, lo que es aún más importante, a escala política. Ello hará que ganen protagonismo y se les empiece a tener en cuenta. Ésta - y que "les respeten"- son, por otra parte, las demandas que más he escuchado en boca de miembros y representantes de esos colectivos. Es así como se va incorporando el español a los servicios. Primero, serán rótulos dispersos y esfuerzos más o menos puntuales y voluntarios. Más tarde, según aumenta la población, a las iniciativas privadas se van sumando las públicas lo que, además de contribuir a regularizarlas, las institucionaliza. De este modo la lengua española llega a ser ubicua.

Hospitales, bomberos y cuerpos de seguridad ciudadana fomentan o promueven, de un modo $u$ otro, las habilidades lingüísticas de sus miembros. Los médicos del hospital Presbiteriano de Nueva York, por ejemplo, vinculado a la universidad de Columbia y situado en el corazón de Washington Heights, foco de concentración dominicana, reciben al incorporarse un curso intensivo sobre términos y conocimientos básicos relacionados con el área, formación que con-

\footnotetext{
${ }^{4}$ Un ejemplo de ello lo ofrece Washington Heights en el Alto Manhattan -conocido como "Dominican Heights" o "Quisqueya Heights" por sus residentes-, donde casi el 80\% de la población es de origen dominicano. Varios de los recintos escolares, ocupados mayoritariamente por chicos de ese origen, poseen nombres significativos para la comunidad (Juan Pablo Duarte, Gregorio Luperón, Hermanas Miraball, etc.). Asimismo la Av. de San Nicolás (St Nicholas Av.) cambió en 1999 a Boulevard Juan Pablo Duarte el "padre de la patria dominicana". E igual ocurre en el resto de lugares con fuerte presencia hispana. (entrevistas y notas de trabajo de campo).
} 
tinúan en otros cursos a lo largo del año. En Texas los agentes de policía deben superar un curso de español, que costea la institución, para obtener el grado de suboficial. En Phoenix (Arizona), en julio de 2002, se puso en marcha en un parque de bomberos el primer programa de inmersión para aumentar la dotación de miembros bilingües. El proceso afecta igual a la esfera educativa. En Dallas (Texas), cuyo distrito escolar es más de la mitad hispano (57\%), y cerca del $30 \%$ con limitaciones en inglés, se aprobaba, en octubre 2002, financiar con un millón de dólares la formación en español conversacional de los docentes con algún conocimiento previo de español. Los acreditados como bilingües incrementarán en 3000 dólares el salario anuals.

A escala nacional se añaden continuamente nuevas acciones ${ }^{6}$. La Seguridad Social, la Reserva Federal y el Departamento Federal de Educación, entre otras entidades, incluyen el español en sus páginas web y el último ha iniciado un programa específico dirigido a latinos. Otras instituciones - entre ellas, la Oficina del Censo y la General Accounting Office (GAO), brazo investigador del Congreso- ofrecen la versión en español de algunos de sus informes. A fines de 2003 se presentó en Washington un portal que unifica la información procedente del Gobierno (www.espanol.gov) y desde el que se puede efectuar gestiones y consultas en español. Un día antes, la red de bibliotecas de Nueva York, en el condado de Queens, inauguraba el portal "Bienvenidos a Queens" que permite realizar consultas en español. Y aumentan, a la par, los distritos y municipios (ya rondan los 300) que deben traducir los impresos electorales para cumplir las directrices del Acta Federal de Derechos de Voto 7 . Los ejemplos son numerosos, de ejecución reciente y van en ascenso. Y aunque tras los últimos haya una normativa federal, van unidos igual a la variable demográfica, punto aquí examinado y cuyo alcance atestiguan.

\footnotetext{
${ }^{5}$ Entrevistas: Nueva York (marzo, 2002) y Chicago (agosto, 2002). Sobre las prácticas en los cuerpos de policía, bomberos y docentes, véase: CNSNews.com. (10/07/2002); The Arizona Republic (10/07/2002); y The Dallas Morning News (16/102002).

${ }^{6} \mathrm{En} 2000$ la Administración del presidente Clinton dictó una orden ejecutiva dirigida a hacer más efectivo el punto relativo a la discriminación por razones lingüísticas, cuestión que ya recoge el Acta Federal de Derechos civiles de 1964. Ésta exige a los gobiernos federales y organizaciones subvencionadas disponer de algún sistema para proveer sus servicios en otras lenguas a fin de garantizar el acceso a quienes no saben inglés. Aunque la mayoría de las administraciones aún están intentando cumplir esa orden, algunas agencias ya suministran documentos en español y cursos acelerados a quienes tratan con el público (The Washington Post 25/9/02 y 6/8/02).

${ }^{7}$ La ley exige suministrar todos los servicios que conlleva el ejercicio del voto en las lenguas minoritarias en los distritos y municipios que cuentan con 10.000 residentes que tienen otra lengua materna $o$ si el $5 \%$ de los ciudadanos en edad de voto no domina el inglés. Dicha norma sólo se aplica a las minorías lingüísticas que han sido excluidas tradicionalmente del proceso político: hispanos, asiáticos, nativos americanos y nativos de Alaska. En el condado de Los Ángeles, p. e., en las elecciones de noviembre 2002, se sumaron al inglés otras cinco lenguas: español, tagalo, vietnamita, chino, japonés y coreano.
} 
Finalmente y volviendo, ya para acabar, a las implicaciones de la concentración, ésta significa también fuerza a nivel político, más si alcanzan el número suficiente de electores registrados para que, tras los datos censales, se reconfiguren las jurisdicciones y se creen nuevos escaños. De esta manera pueden llegar a tener sus propios representantes 8 , como poco, obliga al resto a buscar su apoyo. El uso del español se extiende así entre aspirantes y titulares de cargos públicos a la par que se acentúa la conciencia de especificidad y de la legitimidad de sus demandas. Como afirmaba uno de nuestros informantes, nacido en la República Dominicana y concejal electo por uno de los distritos de Manhattan:

"En la ciudad de Nueva York no hay un político que no esté aprendiendo a hablar español. No hay un político que quiera aspirar, para representar la ciudad entera, los cinco condados, que no hable español. El Alcalde, el Defensor del Pueblo, el Controlador, la Presidenta del Condado, todos hablan español. Y los que no lo hablan, lo están aprendiendo, porque entienden que para comunicarse y recibir el apoyo y el respaldo de la comunidad hispana, tienen que hablar el idioma" (Entrevista, junio 2002).

Y así es. Sólo que no ocurre solamente en Nueva York y el resto de enclaves clásicos. También en Minnesota, Wisconsin o Iowa -que han duplicado o más su población latina-, senadores, congresistas y aspirantes aprenden las frases básicas para pedir el voto y pagan espacios en las televisiones de habla hispana, pautas que empiezan a ser comunes entre los candidatos en distritos hispanos que, como poco, se esfuerzan en pronunciar alguna frase ${ }^{9}$. Y si ya vimos a Bush, en las presidenciales de 2000, salpicar sus discursos con su imperfecto español y el 5 de mayo de 2001 - fiesta nacional mexicana - marcó un nuevo hito al difundir su discurso semanal radiofónico en ese idioma, sus esfuerzos por acercarse a la amplia minoría de hispano-hablantes han llegado hasta la web de la Casa Blanca -www.whitehouse.gov- que ya cuelga la opción "en español", un modo explícito de reconocer que ésta es ya la segunda lengua del país.

Y es que tanto las cifras como las expectativas de crecimiento están causando un enorme revuelo en esta vasta área comercial que es la sociedad norteamericana. No hay sector, al que le vaya algo en ello, que se mantenga al margen de lo que

\footnotetext{
${ }^{8}$ Los dominicanos residentes en el Alto Manhattan (Washington Heights e Inwood) lograron así en 1991, tras la redistribución de distritos, el primer delegado en el concejo de Nueva York, Guillermo Linares, que ejerció el cargo hasta 2001. En 1996 le siguió en la Asamblea Adriano Espaillat, nacido como el primero en Dominicana. Cuando Linares cesó al cumplirse el plazo máximo hubo 6 candidatos de igual origen dispuestos a sustituirle. Lo hizo Miguel Martínez, otro miembro de la generación 1,5 como les designa R. Rumbaut. Los otros distritos con crecida presencia latina tienen también representantes electos en la alcaldía, la Asamblea e incluso dos en el Congreso.

${ }^{9} \mathrm{~K}$. Díaz: “Como se dice, Please vote for me”, The Star Tribune (Minnesota), 25 octubre, 2002.
} 
ocurre: las corporaciones y demás agentes económicos; la clase política; organizaciones y líderes de los colectivos, en busca todos de un lugar bajo el sol. Sin olvidar a los gobiernos de los países emisores que redescubren a sus emigrados desde una nueva óptica. Menos aún a los nativistas que, de la mano de poderosos lobbies conservadores, instan medidas anti-inmigración, izan la bandera del "English only" y llaman a la americanización frente a la babel y la amenaza de balkanizacion que profetizan ${ }^{10}$.

Todos van a tener un papel en esta historia e inciden —o pueden-, de una u otra manera, en el rumbo del devenir. Y es que, a pesar de la larga experiencia de Estados Unidos como receptor de inmigrantes, la situación que deparan los nuevos flujos es totalmente insólita. Y no sólo por la diversidad - geográfica, étnica, social, cultural, en formación, etc.- que acarrean, de lo que es buena muestra el grupo que conforma este conglomerado, reducido para más comodidad a la escueta etiqueta de hispanos o latinos. Tampoco sus actitudes hacia la sociedad receptora - a pesar de la devoción que buena parte le guarde — van a poder ser análogas a las de los antiguos inmigrantes. $\mathrm{Ni}$ en el contexto que les recibe siguen rigiendo igual las directrices de antes. Hay demasiada historia entre una y otra ola, y por más que un aforismo predique la posibilidad de que se repita, es difícil que la historia se replique a sí misma.

Pero, antes de pasar a esa parte de la trama, que sobrepasa en buena medida los márgenes de este escrito, acabemos de esbozar el cuadro que sirve de base a nuestro análisis, abundando algo más en las facetas económica y política, vectores señalados en relación a nuestra cuestión.

\section{EL FACTOR ECONÓMICO}

Es evidente que no basta con ser muchos para ser tenidos en cuenta y, menos aún, para ejercer alguna influencia. Pero este conjunto, tan dispar en sí mismo, presenta ciertas notas que hacen que se le pueda "ver" - y auto-percibirse - como una unidad diferenciada, relegando a un segundo plano las muchas diferencias que lo segmentan, lo que le dota de singular atractivo para un mercado voraz siempre a la busca de nuevos clientes. Como señala Silvio Torres Saillant:

"Cuando más de 30 millones de personas pueden verse a sí mismos como una unidad, compartiendo valores, lengua, cultura y aspiraciones, el capital puede acumularse más rápidamente. Los negocios pueden dirigir sus estrategias de mercado

\footnotetext{
${ }^{10}$ Véase, p e., "Multiculturalism's Volatile Mix" de G. Jonas, The National Post, 21/06/2002, o "Too Many" de S. A. Camarota.
} 
y campañas de publicidad con mayor precisión. Los 17,3 millones de hispanos hispano-hablantes dispuestos y capaces de ver televisión, escuchar la radio y leer periódicos son una mina de oro que el comercio está impaciente por explotar" (Saillant, 2002: 447).

Y así es. Sólo que los 17,3 millones que anota Saillant se han transformado, del censo de 1990, al que corresponden, al actual, en más de 28 (el $11 \%$ de los habitantes de Estados Unidos mayores de 5 años). En Estados como Texas, Nuevo México y California la relación es 1 de cada 4. Pero el español no es sólo la segunda lengua del país, también ocupa igual posición en número de hablantes a escala mundial donde reúne a más de 330 millones, factor importante en sí mismo. Y, sobre todo, es el más común en el orbe geográfico contiguo. A pesar de las muchas y substantivas diferencias entre los grupos - raza, clase, origen nacional, etc.- el español es la lengua franca que une a todos.

Si a ello le unimos que el poder de compra de la población hispana alcanzó los 600.000 millones de dólares en 2002, y los ingresos generados por las empresas - 1,5 millones según algunas estimaciones - rondan los 220.000 millones, es fácil entender el interés que despierta la evolución de esta población y los procesos que se están dando. Sólo el valor en dólares del mercado de música latina ascendió el año 2001 a 642,6 millones ${ }^{11}$. Invertir en promover el sabor latino o en abastecer a tan nutrido conjunto es pues un lucrativo negocio.

Si bien ese abultado potencial económico va parejo a unos ingresos por debajo de la media, notables tasas de pobreza, más desempleo y cifras récord de abandono escolar. En efecto, en 2000 el $21 \%$ de los hispanos estaba por debajo de la línea de pobreza y suponían más del $23 \%$ de la población en tal situación, 11 puntos por encima de su cupo en la total. La tasa media de paro era, a su vez, doble a la de la población blanca-no hispana ( $7 \% v s .3,4 \%)$. Entre los dominicanos la primera alcanza al 36\% y el paro al 8,6\%; el 8,2\% requiere de asistencia pública para sobrevivir al igual que el 7,3\% de los puertorriqueños (Logan, 2001; Therrien et al., 2001).

Pero el mercado hispano es ahora una industria multimillonaria que se extiende a través de Los Ángeles, Miami, Nueva York, Chicago y cada uno de los núcleos latinos existentes. El número de empresas creció un 30\% entre 1992 y 1997 (mientras las estadounidenses lo hacían un 7\%), y sus ingresos un $49 \%$ según datos de la Oficina del Censo ${ }^{12}$. En esa fecha sumaban 1,2 millones, daban empleo a 1,3 y facturaban 186.000 millones de dólares. Tres cuartas partes se localizaban

\footnotetext{
${ }^{11}$ Hispanic Business, mayo 2002, pp. 20 y 22; y 16.

${ }^{12}$ Departamento de Comercio de EE.UU. Oficina del Censo. 2002. "Negocios de Propiedad Hispana: 1997".
} 
RIS

REVISTA INTERNACIONAL DE SOCIOLOGIA

№ 36, Septiembre-Diciembre, 2003

MARÍA JESÚS CRIADO

en cuatro Estados: California, Texas, Florida y Nueva York. Cinco de las diez primeras, según la lista anual de Spanish Business Magazine, tienen su sede en Florida y son propiedad de cubano-americanos, el colectivo que detenta la mejor posición en la escala económica y académica ${ }^{13}$.

No obstante, la mayoría de firmas hispanas (1 millón) son "micro-empresas" enfocadas a las necesidades específicas de los inmigrantes: envío de remesas y otros bienes, servicios legales, importación y exportación de productos a y del país, etc. Algunas de estas actividades implican fuertes y sostenidos vínculos con el lugar de origen y constituyen, según han destacado diversos sociólogos, una forma alternativa de adaptación económica de las minorías en las sociedades avanzadas (Bash et al., 1994; Portes, 1996; Portes et al., 2002; Landolt, 2001; etc.). El trabajo de Portes, Guarnizo y Haller sobre transnacionalismo económico en varios colectivos latinos, muestra que los empresarios transnacionales suponen una gran proporción de los auto-empleados en las comunidades inmigrantes así como la dependencia de muchas de estas empresas de la continuidad de los vínculos con los lugares de origen. Aporta, asimismo, nueva luz sobre el perfil de los implicados en ellas que, en contra de lo que pudiera pensarse, no son los recién llegados o quienes ocupan una posición marginal. En conjunto forman parte de la elite de las respectivas comunidades en términos de educación y posición legal, y sus ingresos están por encima de la media salarial de la mayoría (Portes et al., 2002).

El movimiento monetario ha logrado llamar la atención de las grandes corporaciones y entidades financieras que empiezan a reconocer el potencial económico del mercado hispano y orientan hacia él sus estrategias. En los últimos meses grandes bancos y grupos financieros - J.P. Morgan Chase \& Co., FleetBoston Financial Corp., Citigroup, etc.- - han iniciado o ampliado sus programas dirigidos a la población hispana. Durante 10 años sus servicios se reducían a traducir los documentos bancarios al español y las instrucciones de los cajeros automáticos. Ahora elevan el presupuesto publicitario dedicado al mercado de minorías, lanzan campañas en español, renuevan las sucursales en los centros latinos, dándoles un aire más próximo a la estética del grupo mayoritario presente y las llenan de personal bilingüe ${ }^{14}$. Pero no todo queda en cambio de imagen. Varios bancos - Popular y Citigrup entre ellos - ofrecen descuentos a los inmigrantes en las transferencias de dinero a México y algunos empiezan a abrir cuentas que incluyen dos tarjetas: una para el cliente en Estados Unidos, y otra para un familiar en el extranjero ó, como Wells Fargo, permiten transferir de cuenta a cuenta sin que intervenga otra

\footnotetext{
${ }^{13} \mathrm{El} 73 \%$ ha completado secundaria y un $23 \%$ posee un título universitario; en el mexicano, los porcentajes se reducen a $51,0 \%$ y $6,9 \%$, respectivamente (Therrien y Ramírez, 2001).

${ }^{14} \mathrm{El}$ Banco de América, por ejemplo, ha cuadruplicado su presupuesto, que alcanza ahora 40 millones de dólares, en campañas con lemas como "Creemos en ti" (Newsday, 23/06/2002).
} 
entidad reduciéndose el costo. Recogen así algunas de las propuestas del Banco Interamericano de Desarrollo (BID) dirigidas a abaratar el envío de remesas en las que se implicó directamente el gobierno de México siendo secundadas por el de Estados Unidos ${ }^{15}$. Ello no obsta para que muchos sigan teniendo dificultades para lograr un crédito. Citigrup, p.e., deniega préstamos convencionales a hispanos casi 3,5 veces más que a anglos según el informe 2000 de hipotecas para el hogar (Home Mortgage Disclousure, 2000).

Pero quizá la medida más controvertida (y significada) es la aceptación, tanto en entidades bancarias como en otras instituciones, de la matricula consular - una tarjeta laminada con una foto, nombre, dirección en Estados Unidos y fecha y lugar de nacimiento en México- que emiten los consulados mexicanos a sus naturales como documento de identificación ${ }^{16}$. El fuego lo abrió Wells Fargo con el acuerdo firmado en San Francisco con el Cónsul General de México, en noviembre de 2001, para prestar servicios a sus portadores en cualquiera de sus 5.400 sucursales distribuidas en 23 Estados. Hoy, según el gobierno mexicano, ya lo aceptan 200 bancos y varios grupos financieros a nivel local (Wells Fargo, Lone Star, el Banco Estatal de Texas y el Banco de América). Y es que, según cálculos del banco de la Reserva Federal, nada menos que el 25\% de los hispanos de la nación carecen de cuenta bancaria. Muchos pagan altas tasas a agencias por el pago de cheques y a las remesadoras por transferir dinero a sus países. Wells Fargo, por ejemplo, abrió en 6 meses más de 35.000 cuentas a inmigrantes que representaron unos 50 millones de dólares en depósitos sólo en California. Frente a la censura de los grupos contrarios a la inmigración -ProjectUSA, entre otros- que les acusan de transgredir la ley y estimular la inmigración ilegal, los bancos oponen que "no es su responsabilidad preguntar por el estatus legal de sus clientes"17.

\footnotetext{
${ }^{15}$ El envío simbólico de 200\$ por parte de Rosario Marín, responsable del Departamento del Tesoro de EEUU, desde una sucursal del Citybank en el barrio latino de Washington inició la campaña para abaratar el costo del envío de remesas. La iniciativa es parte del programa "Sociedad para la Prosperidad entre EE.UU y México," firmado por los presidentes de ambos países. Según el BID, los emigrados enviaron a México más de 10.000 millones de dólares en 2002 (véase MIF 2003).

${ }^{16}$ Éste constituye otro de los caballos de batalla del gobierno de México que gestionan, entidad a entidad, sus representantes consulares. En septiembre de 2003 recibió el mayor impulso al acordar el Departamento del Tesoro permitir a los bancos que la aceptaran como identificación para la apertura de cuentas (The Wall Street Journal, 19/ 09/2003). En octubre de 2003 ya la reconocían 1.150 departamentos de policía, 350 ciudades, 150 distritos y varios Estados, incluyendo Indiana y Nevada, la aceptan como identificación para obtener la licencia de conducir. Su éxito ha llevado a otros países a imitar ese ejemplo. De hecho, el gobierno de Guatemala empezó a distribuir tarjetas análogas en septiembre de 2002 y también lo hace ya el de Ecuador. El Salvador, Nicaragua, Honduras y Brasil se lo están planteando (The Boston Globe, 11/10/2003).

${ }^{17}$ Las informaciones proceden de entrevistas con representantes consulares en Nueva York y artículos de prensa de distintos medios. Véase entre otros: The Kansas City Star, 25/05/2002; The New York Times, 6/06/2002, The Washington Times, 18 julio 2002, etc.
} 
RIS

REVISTA INTERNACIONAL DE SOCIOLOCIA

№ 36, Septiembre-Diciembre, 2003

MARÍA JESÚS CRIADO

No obstante, el sector que está viviendo una mayor revolución es el de los media, útil del resto a través de la publicidad y uno de los modos en que se hace evidente la presencia hispana en Estados Unidos. Univisión, líder del sector con sede en Los Ángeles, ocupa la $5^{\mathrm{a}}$ posición del país, tras NBC, ABC, CBS y Fox. Llega al $80 \%$ de los hogares hispanos en Estados Unidos a través de un complejo entramado que incluye 50 emisoras propias y 43 afiliadas, una red de cable (Galavisión), el mayor portal hispano de internet (fruto de su unión con AOL) y - tras la compra en 2002 de Hispanic Broadcasting Corp (la primera cadena de radio en español del país) por 3.500 millones de dólares- 65 emisoras de radio. En 2001 NBC compró, por cerca de 3000 millones de dólares, la otra gran cadena de televisión en español Telemundo (15 emisoras propias y 43 afiliadas). Su objetivo: "ofrecer a los anunciantes la oportunidad de alcanzar un paquete de ventas mayor", según declaraba en una entrevista Alejandro Brenes, su nuevo director de noticias (Hoy de Nueva York, 17 julio 2002). Sólo tres años antes, en 1998, Sony había pagado por ella 539 millones.

También la prensa escrita se ha incrementado notablemente, tendencia que abarca a las otras minorías. Así, según el informe anual del Project for Excellence in Journalism (2004), el número de títulos en español pasó de 14 a 35 en la década 1990/2000, mientras que los ingresos en publicidad en el periodo 1990/2002 se multiplicaron por siete (de 111 millones de dólares a 786 millones). Los últimos movimientos en el sector dirigidos a establecer cadenas nacionales es un indicio de la creciente importancia que se concede a este sector. Todo ello contribuye a la extensión del español en los espacios públicos y las actividades cotidianas.

En suma, en lo que atañe a la esfera económica, varios factores apuntan a la persistencia de cierto particularismo en el conjunto hispano y de sus señas diferenciales. El primero es que ya existe $-\mathrm{y}$ se sigue construyendo- todo un entramado productivo y comercial dirigido a este segmento y que funda su razón de ser en necesidades y demandas específicas de la "comunidad" latina. Y un mercado que se construye sobre la base de las diferencias y glosando la especificidad - gustos, valores, idiosincrasia, etc.- no puede permitir que éstas se diluyan. Con lo que es de prever que marketing y publicidad seguirán realzándolas y llamando a mantenerlas. Los media de habla hispana, cuya razón de ser deriva de la presencia de una vasta comunidad hispano-hablante - con dificultades con el inglés y, aún más en el caso de la prensa, con intereses específicos-deberán forzosamente fomentar y reforzar esa dinámica, entre otras razones, para reducir la desventaja de partida frente a los medios anglo y poder mantenerse. Pues, dado el coste de la publicidad, su mayor fuente de ingresos, los eventuales clientes sólo optarán por tal medio si la cuota de audiencia es convincente ${ }^{18}$. Por otra parte, el

\footnotetext{
${ }^{18}$ Como señalaba un asesor en las elecciones a alcalde de Nueva York: "You can reach Hispanics through English media, but you can't reach English-speakers through Hispanic media" [Daily News, 16/7/01].
} 
español resulta cada vez más funcional en el mercado laboral debido a la demanda de personal bilingüe en los enclaves ${ }^{19}$. Asimismo, la preservación de la dotación cultural y el cultivo de los vínculos que les ligan al país de origen constituye para algunos, en ocasiones, la única manera de obtener cierta posición y ascender socialmente (Portes et al., 1999).

\section{LA VERTIENTE POLÍTICA}

Si hay un punto que subrayan todos los sectores activos de la población hispana, es el escaso reflejo del conjunto a escala política, tanto en la participación en órganos de gobierno, como en el ejercicio del voto que, aunque vaya en ascenso, sigue siendo baja. Y, desde luego, en lo que atañe a la primera, si atendemos a la cifra de miembros de ese origen en los órganos legislativos de la nación, resulta claramente escueta: 22 en el Congreso - 3 más de los que había antes de renovarse la Cámara en noviembre de 2002 - y ninguno en el Senado (NALEO 2002). Ello supone el $5 \%$ respecto al total (436) de la primera; lejos, por tanto, de la correspondiente en la población (13,3\%). Claro que si nos retrotraemos a 1990, cuando sólo había 11, aún puede objetarse que ha mejorado. Si bien a escala estatal sí se empieza a advertir mayor presencia - 59 senadores estatales ( 52 Dem. y 7 GOP) y 158 en Asambleas (133 Dem y 25 GOP)-, aunque en los puestos de cabeza aún no han superado la fase simbólica. Sólo uno ostenta el grado de gobernador, el demócrata Bill Richardson, electo en las últimas votaciones en Nuevo México. A ellos habría que añadir los que ocupan cargos a escala local y los designados en las diversas instituciones. En la administración de Bush, p. e., representan casi un 10\% — poco más que en la de Clinton (7\%) - y entre ellos estaba Rosario Marín, la primera latina [mexicana por más señas] al frente del Departamento del Tesoro. Sumando unos y otros serían, según la Asociación Nacional de Latinos Electos y Nombrados (NALEO, 2002), más de 6.000 en el país.

En cuanto a la participación electoral, distintos factores limitan y determinan la capacidad de acción. Unos de orden sociodemográfico - edad, ingresos y

\footnotetext{
${ }^{19}$ En el curso del trabajo de campo encontré varios casos que mostraban la incidencia de este factor, incluso con "efectos retroactivos". Un neoyorkino, p. e., de origen puertorriqueño, anglomonolingüe en origen, lo aprendió de adulto por su negocio. Otra joven, en Chicago, también nacida alli y de igual filiación, razonaba las ventajas laborales que le suponía conocerlo frente a su marido - de análogo origen y trabajo- que no lo hablaba. Y de igual modo, otros informantes - nacidos en México y con más de 20 años en EE.UU-, que se esforzaron en que sus hijas lo aprendieran, referían la utilidad que tenía ahora para una de ellas, abogado de profesión y con mayoría de clientes hispanos. (Entrevistas, Nueva York: 14/4/02 y 25/7/02; y Chicago: 17/8/02).
} 
educación (la variable necesaria y los primeros predictores), puntúan en los rangos más bajos; otros legales - alto índice de indocumentados y bajas tasas de naturalización (el 28\% según el censo 2000, la menor por áreas geográficas)-, más los de índole instrumental y cultural — falta de familiaridad con el sistema político americano y desinterés por las elecciones, entre ellos-(DeSipio y de la Garza, 2002). Ello no obsta para que también a esta arena haya llegado la marea de los datos del último censo. Y es que, según un análisis de la Asociación nacional de funcionarios latinos electos y nombrados (NALEO), en 122 de los 435 distritos electorales de la Cámara Baja (el 28\%), la población latina excede a la tasa nacional (13,3\%). Y aunque los 7,6 millones de votantes hispanos registrados - la mayoría en 14 Estados - no refleje el peso demográfico del conjunto, son más de tres veces los contabilizados en 1972 (2,5 millones) y se calcula que pueden suponer entre 6 y 10 millones en el 2010 (Jamieson et al., 2002; NCLR, 2002).

Para ello no sólo tienen a favor el tiempo (que mejorará el factor "edad"). La amnistía de 1986 -que regularizó a 2,7 millones de inmigrantes; las medidas anti-inmigración de la pasada década, la gradual aprobación de la doble ciudadanía en los países latinoamericanos ${ }^{20}$, el efecto 11 de septiembre - que a la ola de patriotismo que produjo suma no pocos temores ante sus secuelas en la política migratoria - y las campañas dirigidas a ese fin, se han reflejado en los índices de naturalización y de votantes. Con lo que resultan, y cada vez más, un elemento decisivo a nivel estatal y local en las áreas en que se concentran.

Pero además, las bajas tasas de participación electoral y el hecho de que se agrupen en los seis Estados que proporcionan dos tercios de los 270 votos necesarios para alcanzar la Casa Blanca les ha convertido en objeto de deseo para los partidos en liza. Algo que ya avanzaron los comicios de 2000, ratificaron las de noviembre 2002 y reiteran las presidenciales de 2004.

La orientación política de los hispanos - a excepción de los cubanos- viene favoreciendo, como en el resto de minorías étnicas, al partido demócrata —que viene recogiendo el mayor número de votos- y se ha caracterizado —en una y otra opción - por una notable lealtad. Ahí reside una de sus bazas para negociar su lugar en políticas electorales: no cambian y, al tiempo, componen un núcleo de electorado demócrata en los Estados en donde se concentran (DeSipio y de la Garza, 2002). Bajo esa bandera se agrupa, a su vez, la mayoría de candidatos y cargos electos de origen hispano, sea a nivel local, estatal o nacional. No obstante,

\footnotetext{
${ }^{20}$ Entre 1991 y 1997 seis países -México, Brasil, Guatemala, Colombia, Costa Rica, R. Dominicana, Nicaragua, Chile y Bolivia - se sumaron a los cuatro que reconocían la doble ciudadanía (Uruguay (1919); Panamá (1972); Perú (1980) y El Salvador (1983)). Sobre los efectos en la naturalización, ver Jones-Correa (2000).
} 
empieza a advertirse cierta ambivalencia partidaria a la vez que aumenta el sector que se declara "independiente", lo que se refleja en una mayor movilidad en el voto que suele favorecer a la opción republicana ${ }^{21}$.

La diversidad intra e inter grupos, la menor inclinación hacia los demócratas que se advierte en los flujos más recientes, el avance socioeconómico de algunos segmentos (unido, con frecuencia, a posiciones más conservadoras) y el creciente peso de esta población, ha logrado despertar el interés en unos - por ampliar su base electoral- y el temor en los otros - que ven que el terreno que tendían a dar por seguro puede no serlo tanto. Todo ello revierte en una reñida pugna entre ambos partidos por captar la atención de este electorado. Lo cual se explica fácilmente dado el escaso margen que dirimió la victoria de Bush en noviembre de 2000 - 535 votos más en Florida - , la elevada cifra en edad de votar al margen de las elecciones - 15,6 millones, casi tres veces la de quienes votan, según un estudio de La Raza (2002) - y la popularidad del presidente, firmemente resuelto a ganarse al electorado hispano, aunque le lluevan frenos del ala más conservadora de su partido. Y es que con el $40 \%$ de esos votos, Bush - que obtuvo en 2000 cerca del $35 \%$ vs. $65 \%$ de Al Gore- tendría garantizada la reelección, algo que los demócratas intentan que no ocurra.

Ambos partidos han creado un grupo de acción específico dirigido a los hispanos, mantienen páginas web y audiciones semanales en español, son una presencia rutinaria en las ceremonias de ciudadanía, impulsan programas de registro de votantes, sus líderes menudean en las conferencias que convocan las organizaciones latinas y apoyan — además de animar a postularse - a candidatos de ese origen, la mejor baza para atraer votos. Los dos se publicitan como el destino natural de los votos hispanos - unos, por su tradicional defensa de los derechos de las minorías; los otros, por encarnar los valores familiares y tradicionales que suelen atribuirse a los hispanos-y critican y desestiman los esfuerzos del bando contrario al que acusan, bien de poner toda su energía y recursos en una pura campaña de marketing - demócratas a republicanos-, o de fiarse en exceso de un supuesto vínculo natural que les garantiza el voto - republicanos a demócra-

\footnotetext{
${ }^{21}$ Según un reciente estudio de Hispan Telligence (R) (2004 U.S. Hispanic Electorate: Profile, Issues and Projections) el 35\% de los votantes hispanos se declara independiente. Los datos muestran también un descenso del 6,5\%, de 2000 a 2003, entre los votantes hispanos registrados como Demócratas $(40 \%)$, mientras sube la cifra de los republicanos (24\%). Varias encuestas mostraron, asimismo, que el $40 \%$ de los hispanos votó por candidatos republicanos en las elecciones de $2002 \mathrm{e}$ igual ocurrió en el referéndum de noviembre de 2003 en California en el que se decidía la destitución del gobernador demócrata Grey Davis, re-electo en 2002. Cruz Bustamante, de origen hispano y vicegobernador del Estado, sólo logró el 52\% del voto hispano mientras los republicanos recogian el $40 \%$. (Véase Criado, (2003) para un breve análisis sobre esta última elección).
} 
RIS

REVISTA INTERNACIONAL DE SOCIOLOCIA

№ 36, Septiembre-liciembre, 2003

MARIA JESÚS CRIADO

tas-. Los dos se dirigen a esta población como conjunto particular y unitario, con intereses diferenciados, desligado de alguna manera de la población general y cuya peculiaridad exige una atención específica. De modo implícito o explícito hay siempre un énfasis en la etnicidad lo que, en la práctica, se convierte en una celebración de la misma.

La consigna entre los republicanos es lanzar un mensaje de "inclusión" alejándose de las posturas extremas representadas, por ejemplo, por el congresista de Colorado T. Tancredo, que propugna la eliminación de la educación bilingüe y una moratoria de la inmigración. No quieren repetir la experiencia de Pete Wilson, gobernador de California y promotor en 1994 de la Propuesta 187, que negaba los servicios públicos básicos a los indocumentados y sus hijos. Aunque no llegara a implementarse - fue revocada en 1998 por inconstitucional por un juez federal-, impulsó las naturalizaciones y el voto entre hispanos, y supuso la pérdida del Estado.

Por su parte, los demócratas reiteran su alineación tradicional con las demandas de las minorías y las inquietudes de los inmigrantes. Así, A. Gephardt, líder en la Cámara Baja hasta el descalabro electoral de noviembre 2002, anunció en la reunión anual de La Raza (Miami, julio 2002) la presentación de un proyecto de Ley que, de haberse aprobado, habría supuesto la legalización de 3 a 4 millones de indocumentados de los que del 60 al $70 \%$ serían hispanos. Es éste uno de los temas que toca de lleno al conjunto latino, al que ya intentó dar una salida Clinton en 2000 -el proyecto fue bloqueado por los republicanos-y que ha vuelto a poner sobre el tapete Bush, en enero de 2004, con su propuesta de reforma migratoria.

Esbozada como un conjunto de principios, más que un proyecto concreto, el plan apuesta por la clásica opción del trabajador temporal, en una línea similar al Programa Bracero, vigente de 1942 a 1964, o el guestworker program extensamente utilizado en Europa durante los años 50 a 70 . De aprobarse -muy improbable al tratarse de un año electoral - permitiría regularizar la situación de unos 8 millones de indocumentados siempre que residieran en los Estados Unidos el 7 de enero y facilitaría la entrada de aquellos que contaran con empleo y sus patronos pudieran demostrar que no encuentran nacionales para ese trabajo. En tal caso, se les dotaría con un permiso de trabajo temporal por un periodo inicial de tres años renovable por otros tres más, tras los que deberán retornar al país. $\mathrm{La}$ indefinición del proyecto, los diversos problemas que plantea, y la dificultad de que llegue a término pone de manifiesto la clara intencionalidad electoral que hay tras él.

Y es que, si en 2001 el presidente Bush anunció una serie de medidas a favor de los inmigrantes irregulares, restringido a los mexicanos, es evidente que no podía iniciar el próximo ejercicio electoral sin efectuar algún gesto en ese sentido. 
Más, cuando la situación ha llegado a tal punto que entidades civiles y públicas han acabado por recurrir a instrumentos alternativos (de lo que son un ejemplo las matrículas consulares que mencionamos antes) para paliar en alguna medida los efectos de la parálisis federal.

Unas semanas después de anunciar Bush su propuesta, el grupo de trabajo sobre inmigración del Caucus demócrata de la Cámara Baja presentaba su alternativa de reforma, más inclusiva, en la que, junto a la regularización de los indocumentados aborda la situación de los estudiantes indocumentados - cuestión que está dando lugar a encontrados debates en los órganos estatales saldándose con resultados dispares en unos y otros-y apuesta por un programa de trabajadores temporales que garantice que puedan solicitar la residencia permanente.

Además de las variadas ofertas de reforma migratoria, el afán por llegär al electorado hispano se refleja, asimismo, en el aumento del gasto en publicidad en las televisiones de habla hispana, que superó los 16 millones de dólares en las elecciones de $2002^{22}$ y el uso creciente del español en las campañas. Así, si las elecciones de 2002 fueron testigo del primer debate político en español entre aspirantes a gobernador de la historia de los Estados Unidos ${ }^{23}$ (Texas, 1 de marzo de 2002), en septiembre de 2003 los candidatos a la primarias demócratas inauguraban la tanda de debates previstos en la precampaña electoral presidencial con el primero bilingüe $e^{24}$. Moderado por una periodista de Univisión - que les dirigía preguntas en español y en inglés indistintamente-y un periodista del canal público PBS, prácticamente todos los candidatos leyeron o dijeron, con más o menos fortuna, algunas frases en castellano (The Washington Times, 4/09/2003).

El uso del español se justifica no sólo por la clara preferencia que revelan los sondeos ${ }^{25}$. También ayuda a neutralizar la hostilidad que muchos hispanos han padecido - y aún padecen - frente a su lengua, y que sigue suscitando fuertes recelos. La prohibición de utilizarlo, que imperó durante décadas en muchas escuelas, persiste en docenas de empresas, instituciones y la administración

\footnotetext{
${ }^{22}$ Sobre un examen de este último aspecto puede verse el trabajo de Alan Segal (2002).

${ }^{23}$ En Florida se han celebrado debates antes en español pero sólo en las elecciones municipales.

${ }^{24}$ El acto tuvo lugar en Albuquerque (Nuevo México) y su anfitrión fue el gobernador del Estado de origen hispano Bill Richardson, cuyo nombre se ha barajado como posible candidato a vicepresidente.

${ }^{25}$ Un sondeo interno del Comité Nacional Republicano (RNC) mostró que el 75\% de los hispanos creen que los políticos deberían hablarles en español en vez de en inglés, así como que la preservación de su lengua nativa es una de las 5 cuestiones más importantes en sus vidas (The Washington Times. 20 mayo, 2002).
} 
de un buen número de Estados, espoleados por movimientos como English Only ${ }^{26}$, y se refleja igualmente en la eliminación virtual de la educación bilingüe ${ }^{27}$. Que el presidente de la nación y cargos públicos se esfuercen en hablarlo, aunque sólo lleguen a hilar algunas frases, tiene un fuerte impacto psicológico y traslada varios significados. No sólo es un signo de deferencia o "respeto" — como declaraban Jeb Bush en la pasada campaña o Rudy Fernández, ejecutivo del Comité Nacional Republicano ${ }^{28}$ - también emite un mensaje de "normalidad" sobre la utilización de la propia lengua e informa del interés por comunicarse y establecer puentes. Algo que tiene un mayor impacto al provenir de quien detenta el poder y por su contraste frente a la peculiar arrogancia anglo.

Las organizaciones hispanas son, por otra parte, plenamente conscientes del poder que están adquiriendo sus votos y exigen, cada vez más, propuestas concretas al tiempo que advierten de la coincidencia en prioridade ${ }^{29}$ con la población general y frente a la tentación de sustituirlas con meros discursos en español o fijarles a una sola enseña. Ello se refleja en la febril actividad que desarrollan todos los sectores dirigidas a fomentar el interés por la participación política, bien como electores o como dirigentes. Desde las campañas para estimular la naturalización -el primer paso y principal obstáculo-y el registro como votantes, el entrenamiento en técnicas de liderazgo, o los numerosos grupos de trabajo y conferencias que impulsan, dan cuenta del esfuerzo por movilizar a los miembros de estos conjuntos. Cabe señalar, en este sentido, el vasto y rico tejido asociativo

\footnotetext{
${ }^{26}$ En marzo de 2002 Iowa se convirtió, con el voto del $80 \%$, en el $27^{\circ}$ Estado -el décimo desde 1995 y el $25^{\circ}$ desde 1981- que declaraba el inglés lengua oficial. Asimismo, en agosto de 1996, el Congreso aprobó con amplio margen [259 vs. 157] el English Language Empowerment Act, primer proyecto de ley que oficializaba el inglés a nivel federal. El Senado, consciente del veto de Clinton, relegó la medida. De aprobarse, habría prohibido la mayoría de publicaciones federales en otras lenguas, revocado el derecho de voto bilingüe, restringido las ceremonias de naturalización al inglés y protegido a los anglo-hablantes de "discriminación". En febrero de 2003 el representante republicano por Iowa, S. King, presentó una propuesta similar -The English Language Unity Act of 2003- para su debate en el Congreso (véase Criado, 2003a).

${ }^{27}$ Tras la aprobación en junio de 1998 (con el $61 \%$ a favor) de la Propuesta 227 (English for the Children) que prohíbe la educación bilingüe, su promotor -Ronald Unz- ha impulsado iniciativas similares en otros Estados logrando que se sumaran Arizona (2000) y Massachussets (nov. 2002). En Colorado se votó una iniciativa paralela pero no tuvo éxito. (véase Criado, 2003a).

${ }^{28}$ The Washington Post, 31/10/2002 y The Star Tribune (Minessota), 25/10/2002.

${ }^{29}$ Esto es, educación, economía y seguridad a lo que se añade la política migratoria, derechos civiles y política extranjera. La primera es la mayor inquietud entre los latinos, pues sus jóvenes detentan la tasa más elevada de abandono escolar. En 1998, el 30\% no acababa secundaria frente al $7,7 \%$ de anglo y blancos no-latinos y el 13,8\% de los afro-americanos (Departamento de Educación de EE UU, 2000). Sobre actitudes electorales entre latinos, véase, NCLR, 2002; L. DeSipio y R. de la Garza (2002); Barreto et al., (2002) y Pew Hispanic Center et al.,: (2002).
} 
existente, que se articula alrededor de un amplio elenco de entidades, más o menos formales, y que informa del interés por ser parte activa de la sociedad y de la conciencia sobre la necesidad de organizarse. Buena parte de ellas limitan su actividad a Estados Unidos, pero abundan también las que se dirigen o incluso centran su atención en el lugar de origen. Sus fines incluyen desde donaciones y subvenciones de obras públicas ${ }^{30}$, a objetivos políticos (doble nacionalidad, voto en el exterior, compromiso electoral etc.).

La arena política se extiende ahora -y en ambos sentidos- por encima de las fronteras nacionales. Así, políticos norteamericanos empiezan a incluir en sus itinerarios los países de origen de las minorías latinas dominantes, al igual que se han convertido en rutinarias las visitas de dirigentes y cargos públicos de estos países a las zonas en las que se concentran los grupos emigrados. El primer viaje al exterior de Bush, tras su elección, fue a México; George Pataki, gobernador de Nueva York, y su alcalde, Michael Bloomberg, ambos republicanos, e incluso candidatos, se desplazan a la R. Dominicana ${ }^{31}$ y a Puerto Rico. También Fox tras su victoria, y antes de tomar posesión de su cargo, viajó a Nueva York para reunirse con los grupos mexicanos que le habían apoyado desde el exterior y contribuido a impulsar su campaña (entrevista, agosto 2002). Y éste es también un destino habitual de autoridades y representantes de los partidos de la República Dominicana - que suman numerosos afiliados en Estados Unidos-, al igual que Texas, California, Arizona o Illinois lo son para sus homólogos mexicanos. Unos y otros vienen y van en busca de apoyo - financiero y/o electoral- ampliando así el radio de acción e incidencia.

Es evidente el efecto positivo de los viajes de políticos "anglo", cubiertos ampliamente por los media de ambas lenguas, a los lugares de origen de las minorías inmigrantes, que suelen ir unidos a alguna aportación u objetivo material y contar con la presencia de cargos electos de ese origen. En cuanto a los países emisores, la creciente importancia de los emigrados - vía remesas y contribución

\footnotetext{
${ }^{30}$ Un ejemplo de ello son las Home town association. Sólo las mexicanas sumaban en 1998 unas 500 según Luis Escala Rabadán, del Colegio de la Frontera Norte (datos facilitados por el autor, Chicago, agosto 2002).

${ }^{31}$ El 19 de febrero de 2002 G. Pataki se convirtió en el primer gobernador de Nueva York que visitaba la R. Dominicana, importante fuente de votos. El azar o un cruce de agendas hizo que la visita coincidiera con la de Andrew Cuomo, uno de los candidatos del partido demócrata que, de haber ganado las primarias (se retiró a fines de agosto en plena campaña), habria sido su rival en las elecciones de noviembre 2002 (New York Times, 20/02/2002). El 26 de julio de 2002 era el alcalde de la ciudad, $\mathrm{M}$. Bloomberg, quien realizaba su segunda visita a la isla (la primera fue en noviembre del 2001 a raíz del siniestro del vuelo 587 sobre el condado de Queens). Todos sumaron a la entrevista con el presidente L. Mejía, un breve recorrido por las calles de la isla.
} 
RIS

REVISTA INTERNACIONAL DE SOCIOLOCIA

No 36, Septiembre-Diciembre, 2003

MARIA JESÚS CRIADO

a proyectos de desarrollo local-, la influencia sobre el voto de los coterráneos y el apoyo financiero a campañas y partidos les convierte en actores relevantes en la política interna, a lo que se suma el valor potencial como aliados y mediadores frente a Estados Unidos. Ello ha impulsado un cambio de orientación hacia éstos que se plasma en una serie de acciones y programas dirigidos a afianzar sus lazos con los países y comunidades de origen. La actividad desplegada es muy abundante e incluye tanto medidas internas - doble ciudadanía, voto en el exterior, etc.- como en Estados Unidos, a fin de facilitar una inserción más completa de los emigrados. El ejemplo más paradigmático en este sentido es México que cuenta incluso con una entidad específica a cargo de esas relaciones (Consejo Nacional para las Comunidades en el Exterior, creado en agosto 2002 en sustitución de la anterior) y ha puesto en marcha múltiples iniciativas de distinta índole ${ }^{32}$. En este marco, la concesión de la doble ciudadanía se complementa con campañas en las que se promueve la naturalización y organización de los emigrados (Goldring, 1998; Guarnizo, 1998; Roberts et al., 1999; Jones-Correa, 2000).

Asimismo, y al igual que anotamos en el apartado previo respecto a las actividades económicas transnacionales, la implicación en la política de los países de origen - significada en algunos colectivos - no es un reducto de los miembros marginales, recién llegados o menos educados. Por el contrario, como muestra el trabajo de Guarnizo y Portes (2001) y corroboré en mi estudio, éstos suelen estar asentados en EE UU y poseer suficiente o elevado nivel de instrucción formal. Es, de igual modo, independiente de la naturalización y no se opone a la participación en la política en los Estados Unidos. Es más, al igual que ocurre con el resto de asociaciones comunitarias y las instituciones delegadas de países emisores, las filiales de los partidos de origen promueven de modo activo la naturalización entre los inmigrantes y la participación política (entrevistas NYC, verano 2002).

La participación política no se agota, como es bien sabido, en el ejercicio del voto, aunque sea la práctica más notoria y fácil de contabilizar. Hay otras muchas maneras de incidir en la vida pública que son accesibles también a los no ciudadanos, por un lado, o desde la distancia, por el otro. Si la base que funda

\footnotetext{
${ }^{32}$ Además de las citadas, cabe anotar el Programa para la Comunidades en el Exterior (1990), enseña de esta línea (www.sre.gob.mx/acerca/organigrama/pcme.htm), el Programa Paisano (www.paisano.gob.mx); el programa 3x1; e-México; Ayuda a una micro-región, etc. Cabe destacar, en este caso, la implicación de los distintos Estados que llevan directamente estos programas. Colombia, por su parte, estableció en 1996 el Programa para la Promoción de las Comunidades Colombianas en el Extranjero. El gobierno de Rep. Dominicana ayudó a fundar la Mesa Nacional Dominico-Americana (1997), cuyo fin es coordinar y promover una agenda común. Y así podrían citarse gran número de ejemplos (Entrevistas NY, 2002. Ver también Guarnizo (1998); Goldring; Landolt (2001).
} 
las demandas en los EE UU reside en la capacidad de movilización social y el voto potencial de una población numerosa y en alza, en el lugar de origen es la fuerza de las remesas - que representan en algunos países una de las primeras fuentes de ingresos y divisas ${ }^{33}$ - la aportación material, estratégica y política -en nombre del patriotismo y la lealtad-, junto a la influencia sobre los resultados electorales ${ }^{34}$. En uno y otro campo los conjuntos latinos desarrollan una extraordinaria actividad que se canaliza normalmente a través de asociaciones de base comunitaria, el mejor indicador, por otra parte, de implicación en la vida pública según Montoya (2002), y eficaces mediadores entre base electoral y partidos (Maxwell, 2002). Nos parece importante destacar las dos caras de esta vertiente pues ambas, de una u otra manera, hacen presentes - y refuerzan- los lazos con el lugar y cultura natal, y contribuyen a remarcar unas señas e identidad diferenciadas.

\section{LA DIMENSIÓN EXPRESIVA (LENGUA, IDENTIDAD Y AFILIACIÓN)}

Cerramos nuestra incursión en este terreno con una breve referencia a los aspectos expresivos y simbólicos de la cultura: la lengua y la auto-identificación o membrecía.

Es bien conocida la tradicional presión de la sociedad americana sobre los inmigrantes para su rápida asimilación en la cultura mayoritaria y la aculturación completa como corolario. La imagen de los agentes del Servicio de Naturalización e Inmigración (INS) alterando los nombres de los recién llegados a su paso por Ellis Island ha quedado grabada en los anales de la historiografia. Pero el marco en el que tiene lugar la nueva ola migratoria -y la latinización de Estados Unidos-difiere sensiblemente del pasado en muchas vertientes y, entre ellas, en lo que atañe a la posición frente a la diversidad y otras culturas. La lucha de los movimientos en pro de los derechos civiles y el pluralismo cultural han dejado una amplia huella en el contexto, patente en una mayor tolerancia de las diferencias y un cuerpo legislativo que hace especial hincapié en los derechos de las

\footnotetext{
${ }^{33}$ Según el informe de 2003 del Banco Interamericano de Desarrollo (MIF-FOMIN) las remesas de los inmigrantes a Latino América y el Caribe superaron los 32.000 millones de dólares en 2002 (un $40 \%$ más que en 2001) y, de mantener el ritmo de crecimiento actual, pueden superar los 300.000 en esta década. Éstas exceden a la ayuda oficial al desarrollo a cada país y en 5 de ellos -Nicaragua, Haití, El Salvador, Jamaica y Ecuador- suponen el $10 \%$ o más del PIB. (Multilateral Investment Fund, 2002 y 2003).

${ }^{34}$ Véase, p. e., Sepulveda: "Money boycott forces talks about voting", The Reno Gazette-Journal, 10/8/2002; y J. Mena: "Mexico's 2006 Race Comes to Santa Ana", Los Ángeles Times. 5/07/2002.
} 
minorías. La asimilación, en su sentido fuerte, ha perdido tantos en el camino y se halla ahora - al menos a escala normativa - francamente devaluada (Glazer, 1993). Ello no obsta para que la segregación y discriminación racial siga vigente, al igual que tampoco ha habido mucho avance respecto a las lenguas foráneas que despiertan hoy aún más suspicacia y oposición que antes (Numberg, 1997; Crawford, 1999; Portes y Rumbaut, 2002). Ambas forman parte de los obstáculos y dilemas que deben enfrentar los inmigrantes y sus descendientes en el camino hacia su integración y se oponen al deseo de salvaguardar el legado cultural particular.

La exigencia de la asimilación -y aculturación —lingüistica, se hace patente en las propuestas de los movimientos nativistas del tipo US English, a los que ya hemos aludido en páginas previas, y el desinterés - cuando no animadversión— hacia la educación bilingüe. Una actitud que, dados los muchos elementos, publicidad y resultados que tiene en contra, encuentra amplio eco entre los padres hispanos, inquietos por el futuro de los más jóvenes. Es éste, asimismo, uno de los hallazgos que más me sorprendió en el curso del estudio: la disociación entre la afirmación identitaria y el deseo de que perdure en los hijos, claramente expresos, y la escasa resistencia - que se extiende incluso a los miembros más activos y concienciados de la comunidad - al cambio linguístico.

No es de extrañar, por tanto, que la tendencia general entre los miembros de la segunda generación sea, como ya anticipamos al inicio, la pérdida de fluidez en la lengua materna - más o menos completa-y su relegación frente al inglés en un breve plazo. Y así lo corrobora el estudio longitudinal de Portes y Rumbaut sobre segunda generación en dos de las áreas de mayor densidad de inmigrantes, Miami y San Diego ${ }^{35}$. En efecto, mientras casi la totalidad de los jóvenes observados hablaba inglés con fluidez -el $94 \%$ en la primera fase y el $98 \%$ tres años más tarde-, menos de un tercio (29\%) podía comunicarse con facilidad en las dos lenguas al completar secundaria. E igual ocurría a escala de preferencias. El $72 \%$ de los chicos se decantaba por el inglés en el primer tramo de secundaria y aún subía al $88 \%$ al finalizar ésta a pesar de que en casi todos los hogares se hablara una lengua extranjera.

En estas condiciones lo sorprendente es, pues, que alguna otra lengua logre subsistir de alguna manera. $Y$ en este sentido el español ocupa, como subrayan Portes y Rumbaut en el citado estudio, un indiscutible lugar de honor. Ésta es, con diferencia, la que conocen más jóvenes $(56,3 \%)$ y más emplean en el hogar $(34,6 \%)$ y con los pares $(43,8 \%)$. La diferencia respecto a los consecutivos en la

\footnotetext{
${ }^{35}$ El estudio-Children of Immigrants Longitudunal Study (CILS)- recoge datos de más de 5.000 estudiantes de 77 nacionalidades que asistían a escuelas privadas y públicas de ambas ciudades. Véase Portes y Rumbaut (2001).
} 
lista -el tagalo y otras lenguas filipinas $(12,6 ; 2,2 \%$ y $4,0 \%$, en igual orden) y, en tercer lugar, el vietnamita $(6,5 \% ; 5,8 \%$ y $5,1 \%)$ - nos informa de la distancia existente. El español sigue, asimismo, al inglés en orden de preferencia, aunque el margen es grande y se acentúa aún más entre la primera y segunda encuesta $-14,8 \%$ y $6,5 \%$ - indicando la rapidez del giro lingüístico (ver tabla 2). Es, de igual modo, la que reúne mayor porcentaje de bilingües (entre el 39 y el $47 \%$ según nacionalidad), a notable distancia de los dos siguientes - haitiano (15\%) y chino (10\%)- El origen latino es también el principal predictor de conservación de la lengua: los estudiantes de ese origen tenían un $51 \%$ más de probabilidad de mantener la lengua materna. Y aunque hay una fracción importante (65\%)

Tabla 2.

Conocimiento y uso de las lenguas vernáculas entre los jóvenes de $2^{a}$ generación

\begin{tabular}{|c|c|c|c|c|c|}
\hline \multirow[b]{2}{*}{ Lengua } & \multirow{2}{*}{$\begin{array}{c}\text { Conocida por } \\
\text { el informante } \\
\text { [en \%] }\end{array}$} & \multicolumn{2}{|c|}{ Preferida por el informante } & \multicolumn{2}{|c|}{ Utilizada con ... } \\
\hline & & 1992 & 1995-1996 & $\begin{array}{c}\text { los padres } \\
(\%)\end{array}$ & $\begin{array}{c}\text { los pares } \\
(\%)\end{array}$ \\
\hline Creole (Haiti) & 2,7 & 0,5 & 0,2 & 1,3 & 2,1 \\
\hline Español & 53,3 & 14,8 & 6,5 & 34,6 & 43,8 \\
\hline Tagalo & 12,6 & 1,7 & 0,7 & 2,2 & 4 \\
\hline Vietnamita & 6,5 & 2,9 & 1,7 & 5,8 & 5,1 \\
\hline
\end{tabular}

Fuente: A. Portes y R. Rumbaut (2001).

que pierde fluidez en ella, aún logra destacarse frente al $90 \%$ que la desconocen totalmente en los restantes grupos (Portes y Rumbaut, 2001).

Varias son las razones que explican la mejor posición del español, además del diseño de la muestra (efectuada en dos áreas de alta concentración latina). Esto es, junto a la proximidad al inglés, la cifra de hablantes que reúne en el medio social y escolar - que en su caso suma, al tratarse de una lengua franca para los de ese orbe a diferencia de los asiáticos-y el apoyo de instituciones externas entre las que se incluye una creciente red de medios de comunicación (radio, TV, periódicos, etc.). El esfuerzo de los padres se ve así respaldado por un amplio marco externo (Portes y Rumbaut, 2001; Suárez-Orozco et al., 2002).

En cuanto a la afiliación e identidad, es bien conocida la fidelidad que mantienen los miembros de la primera generación a las originales. De ello da cuenta 
RIS

REVISTA INTERNACIONAL de SOCIOLOCIA

№ 36, Septiembre-Diciembre, 2003

MARÍA JESÚS CRIADO

la persistencia de la idea de retorno y las múltiples formas en que se manifiesta el arraigo a las referencias de partida: resistencia a la naturalización, implicación en asociaciones de base comunal, contribución a las zonas de origen, fidelidad a los símbolos y fiestas nacionales, etc. Menos fácil lo tienen los jóvenes que deberán elegir entre las opciones a su alcance, lo que hace su auto-identificación más compleja e inestable. En este sentido, lo más destacado, según el estudio de Portes y Rumbaut, es el desplazamiento entre las distintas etiquetas al final de la adolescencia; de signo positivo, para la ligada al origen nacional parental y a la pan-étnica, y negativo respecto a la identidad "americana". Entre los mexicanos, por citar un ejemplo, el $41 \%$ opta por la primera en la segunda fase del estudio ( $23,5 \%$ más que en la primera) mientras que sólo un $1,2 \%$ elige la "americana" ( 2 puntos menos que en la previa).

Mis observaciones en el trabajo de campo corroboran ese giro y el momento en que se da. Distintos entrevistados vinculaban, así, el descubrimiento de la identidad nacional entre los jóvenes de la clase media con la entrada en la universidad. Esto tenía un reflejo directo en la incorporación de símbolos - exposición de la bandera del país, tatuajes, etc.-, la implicación o creación incluso de asociaciones vinculadas a la nacionalidad de referencia o al colectivo pan-étnico y la instrucción formal del español, entre otros. Ello es un indicio de la toma de conciencia e incorporación de la definición social que les circunda y la posición que les atribuye. Y así lo señalan también Portes y Rumbaut en el estudio citado.

En otro orden, varios factores dificultan una plena identificación con la sociedad americana y contribuyen a reafirmar la originaria. Entre ellos, la discriminación y segregación que padecen como miembros de una minoría étnica y como inmigrantes. Esto puede llevar a procesos reactivos en los que la lengua y cultura materna y la adscripción inicial se convierten en símbolos de orgullo frente a la amenaza externa; es lo que Portes y Rumbaut $(1996 ; 2001)$ denominan etnicidad reactiva. Por otra parte, la rígida estructura racial de la sociedad norteamericana se opone a la tradición mestiza que troquela las sociedades latinoamericanas y a la experiencia acarreada desde el contexto de procedencia. En este sentido, la inmigración implica, y en especial para quienes proceden de países caribeños, toparse con el componente racial particular, relegado, o incluso inadvertido, en la sociedad de origen ${ }^{36}$. La fractura de la identidad personal y la reelaboración posterior, que sigue a la inmigración, debe contemplar, pues, este nuevo elemento, la "tercera raíz", como la denominan los académicos dominicanos, para quienes el arribo a Estados Unidos supone el descubrimiento de la propia "negritud".

\footnotetext{
${ }^{36}$ Como nos señalaba una entrevistada: "En Dominicana la gente se sienten muy blancos; muy europeos; negros..., son los hatianos..." (Entrevistas en NYC, marzo y mayo 2002) (la cursiva es mía).
} 
Asimismo, las raíces indígenas coloca a buen número de los otros conjuntos en una posición ambigua en la escala racial acentuando, así, la percepción de diferencia. La elevada cifra que desecha las etiquetas que propone el censo 2000 en la pregunta sobre "raza" y opta por "alguna otra" - $42 \%$, frente al $0,2 \%$ entre los "no hispanos"- puede ser indicio de estos elementos ${ }^{37}$. Y así lo corrobora también el elevado índice (59\%) que, en un estudio conjunto del Washington Post, la Fundación Kaiser e investigadores de Harvard, descartaba cualquier similitud tanto con los anglos como con la población afroamericana ${ }^{38}$.

A su vez el pensamiento multicultural, orientación ideológica del momento, instituye el valor de la diversidad, exaltando la etnicidad y culturas de origen, e impugna - en cuanto horizonte normativo - la asimilación. En esta línea cabe interpretar las palabras de una entrevistada - representante consular en Nueva York y antes en Los Ángeles- que refería el renacer de la comunidad como tal, y la recuperación de las raíces, al descubrimiento de lo hispano por parte de los americanos (NY, mayo 2002). Esto, unido a la visión positiva del hecho migratorio que distingue a EE UU de los países europeos - y al hecho positivo de que el migrante de hoy es también ciudadano y, por tanto, votante, o puede serlo mañana - se refleja en la presencia habitual de autoridades y representantes en los actos que afirman la identidad particular (desfiles, festivales, etc.), ligados a conmemoraciones nacionales (independencia, etc.), en los que se suceden (al igual que en los de carácter reivindicativo) las aclamaciones al país y se ensalza el apego y la fidelidad a la identidad y herencia cultural original. Y, aunque no deje de ser un práctica rutinaria, y con una marcada finalidad electoralista, es evidente que ello no anula el beneplácito que supone y su efecto afirmativo, contribuyendo a la vez a contrarrestar la etnicidad reactiva.

Hay, asimismo, al menos dos diferencias de índole histórica frente a los emigrados en la otra gran ola migratoria que merecen destacarse pues tienen que ver con la cuestión considerada. Una incumbe a la posición respecto al propio país y la de éste en el universo simbólico, y la otra, a las relativas al de acogida. En cuanto a la primera, mientras que los grupos europeos venían de Estados en proceso de configuración (italianos o alemanes), o representaban sectores disidentes con la marcha de ese proceso (irlandeses, húngaros) (Guarnizo, 1998), en el caso de los latinos hay por medio una larga historia de colonización, afirmación nacional y lucha contra el dominio externo. El nacionalismo, la exaltación patriótica, conforman un nudo central en el proceso de socialización y están, por tanto, muy arraigados. Y a su vez, si para los primeros Estados Unidos era ante todo una tierra en la que cumplir proyectos, para los

\footnotetext{
${ }^{37} \mathrm{De}$ dos restantes, el $47 \%$ se declara 'blanco' y un $6 \%$ afirma pertenecer a dos o más razas, frente a $2 \%$ que elige esa opción en el resto de la población. (Ver Grieco y Cassidy, 2001 y Singer, 2002).

${ }^{38}$ Véase A. Goldstein y R. Suro: "A Journey in Stages", The Washington Post, 16 enero 2000.
} 
R I S

REVISTA INTERNACIONAL DE SOCIOLOGIA

№ 36, Septiembre-Diciembre, 2003

latinos constituye la nueva cara -y actualización— del viejo imperio. Éstos acumulan experiencias de su ingerencia directa en el orden político, económico e incluso territorial, de sus países y tienen conciencia, igualmente, de que la reestructuración económica que impulsa su diáspora no es ajena a la honda asimetría frente al vecino del norte (Torres-Saillant, 2002). Todo ello acentúa la dificultad para una plena identificación con la sociedad huésped y la inclinación a reivindicar la afiliación particular, ligada al origen o la ascendencia.

Por otra parte, también los países emisores juegan (o tratan) un papel en esta vertiente a través de las acciones y programas a los que ya hemos aludido en apartados previos. Además de los efectos indirectos que puedan derivarse de las medidas que atañen a otras áreas, todos tienen proyectos específicos en el campo cultural. México, p. e., incluye entre sus objetivos el fomento del español y hace un gran hincapié en la esfera educativa. La R. Dominicana tiene una presencia activa a través de la Casa de la Cultura. Junto con ésta, su Secretaria de Estado de Cultura organizó en agosto de 2002 el Primer Foro Consultivo en NY para debatir el Plan Decenal de Cultura que contó con una amplia y cualificada representación de la comunidad (trabajo de campo). Su inauguración coincidió en fecha con la de los V Juegos Patrios en los que participaron equipos deportivos de la isla, Puerto Rico y Canadá junto a los de varios Estados de la unión (Nueva York, Nueva Jersey, Rhode Island, Florida, etc.) (trabajo de campo, agosto, 2002). Los ejemplos son cuantiosos y la tendencia es a aumentar.

Finalmente, las nuevas tecnologías y la facilidad y rapidez del transporte facilitan la comunicación y actualización de vínculos con los países de origen. Si los unos posibilitan el contacto de los más jóvenes con la cultura materna - no fueron pocos los entrevistados que apuntaron cómo gracias a ello sus hijos aprendieron español-, los otros aportan nuevos medios de intercambio entre los emigrados y sus lugares natales. Aumentan, por ejemplo, las páginas web que conectan a los naturales de localidades mexicanas con familiares, vecinos e incluso electorado, en Estados Unidos - juchipila.com; jalpazac.com; tulcingo.com; etc.- - y también pude observar experiencias de este tipo en otros conjuntos. A través de ellas se preservan y recrean los vínculos entre los coterráneos y las tradiciones y costumbres del lugar natal.

Por supuesto, aunque no lo hayamos mencionado aún, la actividad transnacional en este área - cultura e identidad - es abundante y comprende a una población más heterogénea que en los campos precedentes. Mencionar, entre ellas, por su repercusión en los más jóvenes, las ligas y torneos deportivos en las que participan equipos de Estados Unidos y del país natal. Un ejemplo de su extensión nos lo da la Federación Deportiva Mexicana del Noreste de los Estados Unidos, que engloba a 450 equipos de softball y cuenta con 25.800 jugadores y unos 27.000 afiliados (entrevistas, junio y julio, 2002). Y como nos decían varios informantes, y entre ellos, el presidente de la organización citada, "el softball aquí, es mucho más que un deporte" (NY, junio y agosto 2002). 


\section{CONCLUSIONES}

Ser visto y suscitar interés es muchas veces la condición para dar cauce primero, y reivindicar después, el derecho a una presencia. Pues si los pares aportan la base para ver común lo que es ajeno al nuevo contexto - expresarse en español, que el sonido de la bachata, el merengue o la ranchera inunde la vía, disponer de los productos habituales o comer una arepa en un puesto en la calle-, la actitud de los disimiles puede reducir esas conductas al ámbito de la privacidad o reforzarlas mediante la aprobación y, más aún, si las celebran. Y una vez que se inicia este proceso llega un momento en que son los agentes externos los más interesados en potenciar la imagen de "población diferenciada" - y apegada a una serie de señas - frente al conjunto global, tanto insistiendo en la supuesta unidad cultural, como enfatizando las a veces igualmente supuestas diferencias.

Los procesos y datos antedichos corroboran la creciente importancia de la población hispana en Estados Unidos. Ésta ha alcanzado ya la masa crítica necesaria para recabar una especial atención de los otros sectores y afirmar su posición en el horizonte de fuerzas sociales. En cuanto a la cuestión inicial, lo observado apunta a una doble respuesta según el plano al que nos refiramos y la vara con que queramos medirlo. Si la pregunta se limita a si perdurará lo hispano en Estados Unidos, la respuesta no puede ser otra que un resuelto sí. De hecho, el español es evidente en cada segmento de la vida estadounidense, hay ya una elaborada infraestructura que lo apoya y los intereses que le circundan tenderán a darle aún mayor solidez. La continuidad de los flujos, la cercanía a los lugares de origen, las nuevas tecnologías de la información, el interés de corporaciones y políticos en cultivar dicho público, sin olvidar la ideología multicultural y la doctrina normativa del país frente a los inmigrantes - positiva e integradora-, que aportan la legitimidad necesaria, avalan la evolución en esa línea. Y lo mismo cabe decir en cuanto a la alineación con una identidad diferenciada. Entre otras razones, además de las citadas, por lo difícil que le resulta a su vez al ciudadano americano medio verse reflejado - e identificarse - con el resto de palos que tiene hoy la baraja.

Otra cuestión es lo que ocurrirá a nivel individual, así como el alcance y rango social del español. Si permanecerá mayormente como referente simbólico, reducido al intercambio espontáneo con los pares y a la dimensión expresiva y comercial (de bienes o votos) - lo que fía su transmisión al esfuerzo e interés particular y seguirá fomentando la aculturación lingüística de las nuevas generaciones-, o rebasará esos ámbitos afirmando su posición y validez a otras escalas. Por ahora, lo observado muestra que la tendencia, aun en aquellos que tienen un perfecto dominio de la lengua, es saltar al inglés en cuanto la conversación cambia de foro. Se echa de menos, en este sentido, una conciencia más extendida sobre la necesidad de cultivarlo entre los jóvenes y el perjuicio de su pérdida. Es más, no es extraño que se dé por hecho y acepte como normal o, en todo caso, que se fie 
su futuro al albur del ambiente. Se entiende, de un lado, que es el precio a pagar por integrarse y ascender socialmente. Y, de otro, la ligazón natural que se da por si misma. "Como el agua y el pez", según expresión gráfica de un entrevistado ${ }^{39}$ (NYC, agosto 2002). Y nadie duda que ello sea así. Sólo que no hay reguero que resista el batir del océano.

No obstante, tampoco cabe hacer un gran desgarro de vestiduras. Aunque ya sea posible vivir en Estados Unidos en español, el hecho objetivo es que sólo quienes dominan el inglés pueden llevar una vida más plena y tener acceso a oportunidades. Es comprensible, pues, que, ante las dificultades escolares o las deficiencias de la - mal llamada - educación bilingüe, los padres opten por relegar su lengua (en la escuela e incluso en el hogar). Pero con independencia del componente afectivo y los beneficios psico-sociales asociados - mayor autoestima y expectativas académicas y menor disonancia cultural entre generaciones (Portes y Rumbaut, 2001; Portes y Hao, 2002) - el bilingüismo tiene un notable valor en sí mismo en un mundo - y economía - cada vez más global e interconectado. Y, de hecho, no faltan voces que lo recuerdan. Por lo que es de esperar que, a medida que el español afirme su posición en el espacio social y se amplíe la demanda de personal bilingüe - algo que ya está ocurriendo, como hemos visto-, se empiece a contemplar - y apreciar - de otra manera el potencial natural con que se cuenta.

Por otra parte, la pérdida o el escaso dominio de la lengua materna, no parece afectar - al menos hasta donde alcanzan nuestras observaciones-a la afiliación identitaria, lo que sin duda choca con el presupuesto general que los engarza. Y, aunque ello no deje de suscitar cierta sorpresa en quien lo ve desde fuera, los indicios apuntan hacia un sólido nacionalismo que prescinde del vínculo con la lengua de referencia. Las razones que hay detrás son muy variadas. Pero esto, se sale de los márgenes de este escrito.

En suma, los procesos y factores que circundan a la comunidad latina en los Estados Unidos inclinan a pensar en una asociación entre asimilación y un cierto grado de particularismo, y por tanto, en una bi-culturalidad. El español seguirá consolidando su presencia y es relativamente factible que, al menos en determinadas zonas y a no ser que se frene la inmigración de manera radical - algo que parece difícil一, el bilingüismo vaya en aumento ${ }^{40}$. Ello irá unido, no obstante, a la mejora de las condiciones sociales de sus hablantes que son, como es bien sabido,-las que determinan el prestigio social de una comunidad y de su lengua.

\footnotetext{
${ }^{39}$ Quizá valga la pena anotar que quien asi descarta la necesidad de cualquier tipo de apoyo, es miembro de una prestigiosa universidad norteamericana y está tan comprometido con lo que sucede en su país como para presidir la extensión en EE UU del principal partido político de aquel que cuenta con un buen número de afiliados.

${ }^{40} \mathrm{Cabe}$ señalar, en este sentido, la mayoritaria preferencia por el bilingüismo (en los hijos) que se observa en la última fase del proyecto CILS-III (Portes et al., 2003).
} 


\section{REFERENCIAS BIBLIOGRÁFICAS}

BACHU, A. y M. O'CONNELL (2001), Fertility of American Women: June 2000, Oficina del Censo de Estados Unidos.

BARRETO, M., R. DE LA GARZA, J. LEE, J. RYU. y H. PACHON (2002), A Glimpse into Latino Policy and Voting Preferences, The Tomás Rivera Policy Institute.

BROOKINGS INSTITUTION CENTER ONURBANAND METROPOLITAN POLICY, Racial Change in the Nation's Largest Cities: Evidence from the 2000 Census, www.brookings.edu/urban.

CRAWFORD, J. (1999), Bilingual Education: history, politics, theory and practice, Los Angeles, Bilingual Educational Services, $4^{\mathrm{a}}$ edición.

CRIADO, M.J. (2003a), "En torno al español (en los Estados Unidos): imágenes y actitudes", Center for Migration and Development, Working Paper Series \#03-8, Princeton University. [<http://cmd.princeton.edu/CMD_Working_Papers/wp0308.pdf $>$ ].

(2003 b), "El voto Hispano en las elecciones de Califormia", Análisis del Real Instituto Elcano [ARI No 134/2003] Real Instituto Elcano, 19/11/2003 [http://www.realinstitutoelcano.org/analisis/364.asp].

DEPARTAMENTO DE COMERCIO DE ESTADOS UNIDOS. OFICINA DEL CENSO, Projected Population of the United States, by RACE and Hispanic Origin: 2000-2050.

(2002) Negocios de Propiedad hispana: 1997. CENBR/01-4sp. Oficina del Censo de EE UU.

CAMAROTA, S.A. (2002), "Too Many. Looking Today's Immigration in the Face”, National Review, 19 julio 2002, Center for Immigration Studies [www.cis.org./articles/2002/sac729.html].

DESIPIO, L. y R. DE LA GARZA (2002), "Forever Seen as New. Latino Participation in American Elections", Latinos. Remaking America, edit. por M. Suárez-Orozco y M. Páez, Berkeley, Universidad de California y David Rockefeller Center for Latin American Studies pp. 398-409.

GLAZER, N. (1993), "Is assimilation dead?", Annals of the American Academy of Political and Social Science, vol. 530, pp. 122-36.

GOLDRING, L. (1998), "From market membership to transnational citizenship?: the changing politization of transnational social spaces", L'Ordinaire Latino-Americain, n' 173-174: 167-173.

GOLDSTEIN, A. y R. SURO, “A Journey in Stages”, The Washington Post, 16 enero 2000.

GRIECO, E.M. y R.R. CASSIDY (2001), Overview of Race and Hispanic Origin, Departamento de Comercio de Estados Unidos, Oficina del Censo.

GUARNIZO, L.E. (1998), "The rise of transnational social formations: Mexican and Dominican State responses to the transnational migration", Political Power and Social Theory, vol. 12: 45-94. y Portes, A. (2001): From assimilation to transnationalism: determinants of transnational political action among contemporary migrants, working paper, Center for Migration and Development, Princeton University. 
RIS

REVISTA INTERNACIONAL DE SOCIOLOCIA

No 36, Septiembre-Diciembre, 2003

MARIA JESÚS CRIADO

GUZMÁN, B. (2001), La Población Hispana, Departamento de Comercio de Estados Unidos, C2KBR 0I-3SP.

HAYES-BAUTISTA, D.E., P. HSU, A. PÉREZ y M. I KAHRAMANIAN (2003), The Latino Majority has Emerged, Center for the Study of Latino Health and Culture, Universidad de California de Los Angeles (UCLA).

JAMIESON, A., H.B. SHIN y J. DAY (2002), Voting and Registration in the Election of November 2000, pp. 20-542, Dep. de Comercio de Estados Unidos, Oficina del Censo.

JONES-CORREA, M. (2000), Under Two Flags:Dual Nationaly in Latin America and Its Consequences for the United States, Cambridge, MA, David Rockefeller Center for Latin American Studies.

LANDOLT, P. (2001), "Salvadorian economic transnationalism: embedded strategies for household manintenance, inmigrant incorporation, and entrepreneurial expansion", Global Network, vol. $1 \mathrm{n}^{\circ} 3$, pp. $217-241$

LOGAN, J.R. (2001), The New latinos: Who They Are, Where They Are, Lewis Munford Center for Comparative Urban and Regional Research, Universidad de Albany.

MARWELL, N.P. (2002), "Community-Based Nonprofit Organizations as Political Actors", documento presentado a la conferencia Community Based Organizations and Social Services in the Dominican Community, New School University, NY, junio 2002 (mimeo).

MONTOYA, L.J. (2002), "Gender and Citizenship in Latino Political Participation", Latinos, ed. por M. Suárez-Orozco y M. Paéz. Berkeley, LA y Londres, Universidad de California y David Rockefeller Center for Latin American Studies, pp. 410-425.

MULTILATERAL INVESTMENT FUND (MIF), Remittances to Latin American \& the Caribbean, Inter-American Development Bank 2002.

NATIONAL COUNCIL OF LA RAZA [NCLR], (2002), Mobilizing the Latino Vote, Julio.

NATIONAL ASSOCIATION OF LATINO ELECTED AND APPOINTED OFFICIALS (NALEO) (2002), Latinos Gain New Ground in Congress and State Houses, [www.naleo.org/press_releases/ Press044.htm].

NUMBERG, G. (1997), "Lingo Jingo. English Only and the New Nativism", The American Prospect, vol. 8, n³3, Agosto.

PASSELL, J. (2002), "New Estimates of the Undocumented Population in the United States", Migration Policy Institute, [http://www.migrationinformation.org/Usfocus].

PASSELL, J., R. CAPPS y M. FIX (2004), Undocumented Immigrants: Fatcs and Figures, Urban Institute.

PORTES, A., W. HALLER y L.E. GUARNIZO (2002), "Transnational entrepreneurs: the emergence and determinants of an alternative form of immigrant economic adaptation", American Sociological Review, vol. 67, abril, pp. 278-298. 
PORTES, A. y L. HAO (2002), "The price of uniformity: language, family and personality adjustment in the immigrant second generation", Ethnic and Racial Studies, vol. $25 \mathrm{~N}^{\circ} 6$, pp. 889-912.

PORTES, A. y R. RUMBAUT (1996), Inmigrant America, Berkely, CA, Universidad de California.

(2001), Legacies. The Story of the Second Generation, Nueva York, Universidad de California y Russel Sage Foundation.

RAMÍREZ, R. y G.P. DE LA CRUZ (2003), "The Hispanic Population in the United States: March 2002", US Census Bureau.

ROBERTS, B., R. FRANK y F. LOZANO-ASCENCIO (1999), "Transnational migrant communities and Mexican migration to the US", Ethnics and Racial Studies, vol. 22, n 2, pp. 238-266.

SEGAL, A. (2002), "Records broken: Spanish-language Television advertising in the 2002 Election", John Hopkins Journal of American Politics, Noviembre 2002, [http://www.wcjournal.org/].

SCHMIDLEY, D., U.S. CENSUS BUREAU, CURRENT POPULATION REPORTS, SERIES p. 23-206 (2001), Profile of the Foreign-Born Population in the United States, 2000, U.S. Government Printing Office, Washington DC, [www.census.gov/population/www/socdemo/ foreign/ppl-145.html].

SINGER, A. (2002), American Diversity at the Beginning of the 21st Century: Reflections from the Census 2000, The Brookings Institution Center on Urban and Metropolitan Policy.

SUÁREZ-OROZCO, M. (1999), "Latin American Immigration to the United States", The United States and Latin American: The New Agenda, ed., V. Bulmer-Thomas y J. Dunkerley, Cambridge, MA, Harvard University Press.

SUÁREZ-OROZCO, M. y M.M. PÁEZ, (2002), “The research Agenda”, Latinos. Remaking America. Berkeley, ed. por mismos autores, Los Angeles y Londres: U. de California y David Rockefeller Center for Latin American Studies [Harvard University], pp. 1-37.

SURO, R. (2002), Counting the "Other Hispanics": How Many Colombians, Dominicans, Ecuadorians, Guatemalans and Salvadorans Are in the United States, Washington DC, Pew Hispanic Center.

SURO, R y A. SINGER (2002), Latino Growth in Metropolitan America: Changing Patterns, New Locations, Center on Urban \& Metopolitan Policy y The Pew Hispanic Center.

THERRIEN, M. y R.R. RAMÍREZ (2001), The Hispanic Population in the United States, Series, pp. 20-535, Departamento de Comercio de Estados Unidos, Oficina del Censo de Estados Unidos.

THE PEW HISPANIC CENTER/HENRY J.KAISER FAMILY FOUNDATION (2002), National Survey of Latinos: The Latino Electorate, octubre 2002.

THE PROJECT FOR EXCELLENCE IN JOURNALISM (2004), The State of the News Media 2004, Columbia University Graduate School of Journalism. 
RIS

REVISTA INTERNACIONAL DE SOCIOLOCIA

№ 36, Septiembre-Diciembre, 2003

MARIA JESÚS CRIADO

TORRES-SAILLANT, S. (2002) "Problematic Paradigms: Racial Diversity and Corporate Identity in the Latino Community", Latinos, .ed. por M. Suárez-Orozco y M. Páez, Berkeley, Universidad de California y David Rockefeller Center for Latin American Studies, pp.435-455.

VELTMAN, C.J. (1983), Language shift in the United States, Nueva York, Mouton. 